\title{
MODELO MULTICRITÉRIO PARA APOIAR DECISÕES RELACIONADAS AO DESEMPENHO DA ÁREA DE MERCADO DE UMA EMPRESA DE INFORMÁTICA
}

\section{MULTICRITERIA MODEL TO SUPPORT DECISIONS RELATED TO THE MARKET AREA PERFORMANCE OF A COMPUTER COMPANY}

\author{
Sandro César Bortoluzzi* E-mail: sandro@utfpr.edu.br \\ Sandra Rolim Ensslin** E-mail: sensslin@gmail.com \\ Leonardo Ensslin** E-mail: leonardoensslin@gmail.com \\ *Universidade Tecnológica Federal do Paraná (UTFPR), Curitiba, PR \\ **Universidade Federal de Santa Catarina (UFSC), Florianópolis, SC
}

\begin{abstract}
Resumo: O presente trabalho teve como objetivo construir um modelo de Avaliação de Desempenho para a área de mercado da empresa Seprol Computadores e Sistemas Ltda. Sendo assim, escolheuse a Metodologia Multicritério de Apoio à Decisão Construtivista (MCDA-C) para (i) estruturar e construir conhecimento sobre os objetivos a serem considerados no modelo; (ii) avaliar os objetivos por meio de escalas ordinais e cardinais; e, (iii) sugerir ações de aperfeiçoamento. A pesquisa caracteriza-se como (i) exploratória; (ii) estudo de caso; e, (iii) qualitativa e quantitativa. Os principais resultados da pesquisa foram: (i) identificação de quatro grandes dimensões que respondem pelo desempenho da empresa em relação ao mercado (imagem, clientes, fornecedores e estratégias); (ii) construção de 21 indicadores para avaliar o desempenho das quatro dimensões; (iii) procedimento da avaliação da situação atual da empresa em relação ao mercado, a qual totalizou 62 pontos, em uma escala em que "100" representa o nível bom e "0" representa o nível neutro; (iv) elaboração de recomendações de melhoria, sendo que, se forem implantadas com sucesso, elevará o desempenho da empresa para 76 pontos. Conclui-se que a metodologia MCDA-C cumpriu o papel de avaliar os aspectos intangíveis relacionadas à área de mercado da empresa estudada.
\end{abstract}

Palavras-chave: Mercado. Apoio à Decisão. Avaliação de Desempenho. MCDA-C. Intangíveis.

Abstract: This study aimed at constructing a model of performance evaluation in the market area of Seprol Computadores e Sistemas Ltda company. Thus, we chose the Multicriteria Methodology for Decision Aid - Constructivist (MCDA-C) to (i) structure and build knowledge about the objectives to be considered in the model; (ii) evaluate the objectives through ordinal and cardinal scales; (iii) suggest actions of improvement. The research is characterized as an exploratory, qualitative and quantitative case study. The main results of the research were: (I) the identification of four main dimensions image, customers, suppliers and strategies - which account for the company performance in relation to the market (ii) twenty-one indicators were built to evaluate the performance of the four dimensions, (iii) we evaluated the company's current situation regarding the market, which totaled 62 points on a scale that "100" represents the good level and "0" represents the neutral level; (iv) advices were prepared for improvement, and if they are successfully implemented they will increase the company's performance to 76 points. It is concluded that the methodology MCDA-C has fulfilled the role of evaluating the intangible aspects related to the market area of the studied company.

Keywords: Market. Decision aid. Performance evaluation. MCDA-C. Intangibles. 


\section{INTRODUÇÃO}

Nos últimos anos, intensificaram-se as pesquisas no sentido de verificar o que promove alteração no desempenho das organizações e que normalmente não é gerenciado. Nesse sentido, as críticas comumente encontradas na literatura referemse a avaliar apenas os aspectos tangíveis que normalmente são mais fáceis de mensurar (LEV, 2001; STEWART, 1998; SVEIBY, 1998; KAPLAN; NORTON, 1997; EDVINSSON e MALONE, 1998). No entanto, percebe-se a necessidade de avaliar os aspectos intangíveis, mesmo que sua mensuração seja mais difícil (WERNKE e BORNIA, 2001; BARBOSA; GOMES, 2002; PACE; BASSO; SILVA, 2003; ANTUNES; MARTINS, 2007; BORTOLUZZI; ENSSLIN; ENSSLIN, 2010a).

Assim, argumenta-se ser necessário avaliar e consequentemente gerenciar aspectos como: (i) a imagem da empresa perante o mercado; (ii) o relacionamento com clientes; (iii) o relacionamento com fornecedores; e, (iv) as estratégias para melhorar a competitividade em relação ao mercado de atuação.

Nesse contexto, apresenta-se a pergunta que orienta esta pesquisa: Quais indicadores devem ser considerados em um modelo que pretende avaliar as particularidades do desempenho da área de mercado de uma empresa de informática? Para responder à pergunta de pesquisa, apresenta-se o objetivo geral do presente trabalho: construir um modelo de Avaliação de Desempenho para a área de mercado da empresa Seprol Computadores e Sistemas Ltda.

Com a definição do objetivo geral da pesquisa, enumeram-se estes objetivos específicos: (i) explicitar os objetivos da área de mercado que o decisor deseja maximizar; (ii) identificar a relação de causa e efeito entre os objetivos; (iii) organizar os objetivos em uma estrutura hierárquica de valor; (iv) construir escalas ordinais e cardinais para os indicadores identificados; (v) traçar o perfil de desempenho e avaliar o desempenho local e o global; e, (vi) criar estratégias para melhorar o desempenho da área de mercado.

O trabalho se justifica pela contribuição teórica e prática. A contribuição é teórica, pois discute a literatura de Avaliação de Desempenho (AD) no sentido de comparar métodos tradicionais em relação à metodologia empregada no presente estudo à luz da afiliação teórica adotada. Adicionalmente, o estudo coteja a presença dos elementos considerados importantes na construção de modelo de $A D$ 
segundo a literatura em relação ao modelo construído.

A contribuição prática emerge pela construção de um modelo de Avaliação de Desempenho de uma área pouca gerenciada pelas empresas, pois os objetivos a serem melhorados na área de mercado são, em sua maioria, intangíveis e, sob a perspectiva das empresas, esses aspectos são difíceis de serem mensurados. Adicionalmente, o presente estudo contribui de forma prática para a gestão personalizada (singularidade) dos aspectos que impactam no desempenho da empresa estudada, pois capturam do contexto decisório os aspectos que são relevantes para o decisor. Apesar de o modelo ter validade para o decisor e para o seu contexto decisório, ele traz contribuição prática para outras empresas, visto que pode motivar outros decisores e outras empresas a buscarem a construção de um modelo que atenda ao seu contexto decisório.

Além desta parte introdutória, o artigo apresenta, na seção 2, o referencial teórico; na seção 3, a metodologia da pesquisa; na seção 4, o estudo de caso; e, por fim, as considerações finais do trabalho.

\section{REFERENCIAL TEÓRICO}

Esta seção discute os seguintes aspectos: (i) fundamentos e definições de Avaliação de Desempenho Organizacional; (ii) vantagens e desvantagens dos tradicionais sistemas de Avaliação de Desempenho; e, (iii) Metodologia Multicritério de Apoio à Decisão Construtivista (MCDA-C).

\subsection{Fundamentos e definições de Avaliação de Desempenho Organizacional}

A Avaliação de Desempenho é um tema bastante explorado na literatura, mas raramente sua definição é explicitada (NEELY; GREGORY; PLATTS, 2005). Mesmo em pesquisas em que se define a Avaliação de Desempenho, o conceito apresentado normalmente é genérico, ou seja, o assunto é abordado de forma ampla, o que implica dificuldades para entendimentos sobre o processo a ser realizado (NEELY; GREGORY; PLATTS, 2005; BORTOLUZZI; ENSSLIN; ENSSLIN, 2010b). Nesse contexto, faz-se necessário estabelecer a afiliação teórica dos autores em relação ao tema Avaliação de Desempenho Organizacional, que "é o 
processo de gestão utilizado para construir, fixar e disseminar conhecimentos por meio da identificação, organização, mensuração e integração dos aspectos necessários e suficientes para medir e gerenciar o desempenho dos objetivos estratégicos de um determinado contexto da organização" a partir da percepção do(s) decisor(es) (ENSSLIN; ENSSLIN; PACHECO, 2012, p.75; ENSSLIN et al., 2010).

Com esse esclarecimento, apresentam-se, no Quadro 1, outros conceitos de Avaliação de Desempenho Organizacional encontrados na literatura, e, com base na afiliação teórica adotada no presente estudo, realiza-se uma análise crítica no sentido de confirmar a afirmação de que os conceitos são genéricos/amplos, não permitindo, assim, identificar o processo de construção do modelo de avaliação.

Quadro 1 - Conceitos de Avaliação de Desempenho Organizacional encontrados na literatura

(continua)

\begin{tabular}{|c|c|}
\hline $\begin{array}{l}\text { Avaliar desempenho significa avaliar ou mensurar a contribuição, ou o } \\
\text { resultado, proporcionado à empresa por seus respectivos centros de } \\
\text { responsabilidade. }\end{array}$ & Catelli et al. (1999) \\
\hline $\begin{array}{l}\text { Um quadro completo de Avaliação de Desempenho contempla três } \\
\text { componentes principais: (a) diagnósticos estratégicos; (b) levantamento dos } \\
\text { objetivos/metas, estratégias e projetos atualmente em curso; e, finalmente, (c) } \\
\text { análise de desempenho propriamente dito }\end{array}$ & (MARTIN, 2002). \\
\hline $\begin{array}{l}\text { A medição de desempenho pode ser entendida como o processo de } \\
\text { quantificar ou qualificar o desempenho de um produto ou processo de uma } \\
\text { organização. }\end{array}$ & $\begin{array}{l}\text { Gerolamo; Esposto, } \\
\text { Carpinetti (2003) }\end{array}$ \\
\hline $\begin{array}{l}\text { A análise e a mensuração de desempenho podem ser definidas literalmente } \\
\text { como o processo de se quantificar uma ação, no qual mensuração é o } \\
\text { processo de quantificação, e a ação é aquilo que provoca o desempenho }\end{array}$ & Neely (1995) \\
\hline $\begin{array}{l}\text { A análise das demonstrações financeiras visa basicamente a uma avaliação } \\
\text { do desempenho da empresa, notadamente como forma de identificar os } \\
\text { resultados (consequências) retrospectivos e prospectivos das diversas } \\
\text { decisões financeiras tomadas. }\end{array}$ & Assaf Neto (2003), \\
\hline $\begin{array}{l}\text { Avaliação de desempenho é um processo estruturado de análise de } \\
\text { informações contábeis e financeiras que permite sem o envolvimento humano } \\
\text { analisar o desempenho das organizações }\end{array}$ & $\begin{array}{l}\text { (SANTOS } \\
\text { CASANOVA, 2005). }\end{array}$ \\
\hline $\begin{array}{l}\text { A mensuração do desempenho pode ser feita sob a ótica de valores } \\
\text { monetários, normalmente utilizando dados contábil-financeiros, e/ou sob a } \\
\text { ótica de informações não monetárias. A conjugação de informações de ambas } \\
\text { as naturezas pode levar o sistema de avaliação do desempenho a uma } \\
\text { condição diferenciada no que diz respeito a certas predições para subsidiar o } \\
\text { processo decisório. }\end{array}$ & $\begin{array}{l}\text { Hendriksen e Van } \\
\text { Breda (1999) }\end{array}$ \\
\hline $\begin{array}{l}\text { Um sistema de medição de desempenho eficaz possui necessariamente as } \\
\text { seguintes partes: "1 - métricas individuais que quantificam e eficiência e } \\
\text { eficácia das ações; } 2 \text { - um conjunto de medidas que permita o acesso ao } \\
\text { desempenho da organização como um todo; e } 3 \text { - uma estrutura que suporte } \\
\text { e habilite a aquisição, ordenação, análise, interpretação e disseminação dos }\end{array}$ & $\begin{array}{l}\text { Kennerly e Neely } \\
(2000)\end{array}$ \\
\hline
\end{tabular}


Quadro 1 - Conceitos de Avaliação de Desempenho Organizacional encontrados na literatura

(conclusão)

O modelo de avaliação de desempenho deve sistematizar uma estrutura e linguagem para comunicar a estratégia da empresa, utilizar indicadores para informar os colaboradores sobre os vetores do sucesso atual e futuro, além de englobar iniciativas que ajudam a reduzir o diferencial entre o desempenho atual e o desejado).

Avaliação de desempenho consiste em identificar indicadores de desempenho em quatro perspectivas diferentes (financeiro, clientes, processos internos e aprendizado e crescimento) para que o gerenciamento desses indicadores melhore a performance organizacional

Avaliar o desempenho seria simplesmente a capacidade da organização de atingir seus objetivos usando recursos de um modo eficiente e eficaz.

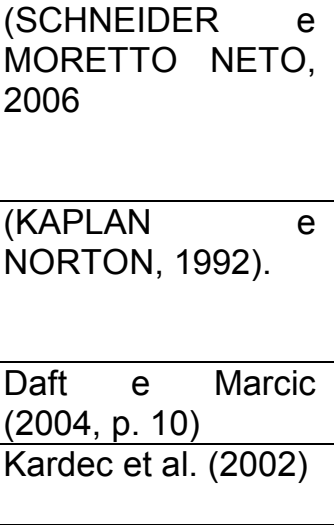

Avaliação de desempenho são guias que permitem medir a eficácia das ações tomadas, bem como medir os desvios entre o programado e o realizado.

Fonte: Adaptado de Bortoluzzi; Ensslin; Ensslin (2010b).

A análise dos conceitos apresentados no Quadro 1 possibilita confirmar a afirmação feita por Neely, Gregory e Platts (2005) de que os conceitos são amplos e que impedem a visualização do processo utilizado para construir um sistema de Avaliação de Desempenho Organizacional. Cabe salientar que muitos autores não apresentam conceitos/definições de Avaliação de Desempenho. No entanto, apresentam aspectos/elementos que devem ser considerados para a construção de sistemas de Avaliação de Desempenho Organizacional, sendo eles:

i. Alinhamento estratégico e identificação da relação causa e efeito entre os objetivos (KAPLAN e NORTON, 2000; YEO, 2003; GARENGO, BIAZZO e BITITCI, 2005; PUNNIYAMOORTHY e MURALI, 2008);

ii. Linguagem clara e holística dos objetivos (KAPLAN e NORTON, 2000; GARENGO, BIAZZO e BITITCI, 2005);

iii. Visão estratégica da organização em função de uma perspectiva futura (KAPLAN e NORTON, 2000; TUOMELA, 2005; JACOBSEN, HOFMAN-BANG e NORDBY, 2005; GARENGO, BIAZZO e BITITCI, 2005; PUNNIYAMOORTHY e MURALI, 2008; HAN e HAN, 2004);

iv. Sistema de feedback e comunicação (TUOMELA, 2005);

v. Medidas financeiras e não financeiras (KAPLAN e NORTON, 2000; YEO, 2003; TUOMELA, 2005; GARENGO, BIAZZO e BITITCI, 2005; CHENHALL e LANGFIELD-SMITH, 2007; PUNNIYAMOORTHY e MURALI, 2008; BORTOLUZZI et al., 2010);

vi. Inter-relacionamento das medidas (SOMENSI e TONTINI, 2001);

vii. Avaliação de Ativos Intangíveis (WERNKE e BORNIA, 2001; BARBOSA e GOMES, 2002; PACE, BASSO e SILVA, 2003; ANTUNES e MARTINS, 2007); 
viii. Particularidades da organização (GOLDSZMIDT e PROFETA, 2004; DUTRA, 2005; CARPES, ENSSLIN e ENSSLIN, 2006; CORRÊA e HOURNEAUX JUNIOR, 2008);

ix. Avaliação qualitativa e quantitativa (GEROLAMO, ESPOSTO e CARPINETTI, 2003; KIMURA e SUEN, 2003);

X. Avaliação global de desempenho (KIMURA e SUEN, 2003; DUTRA, 2005; CARPES; MACEDO, SILVA e SANTOS, 2006; CORREAA e HOURNEAUX JUNIOR, 2008);

xi. Tradução da estratégia em termos operacionais (GOLDSZMIDT e PROFETA, 2004); e,

xii. Múltiplos critérios (DUTRA, 2005; LÖBLER e HOPPEN, 2006; MIRANDA, 2006).

Cumpre salientar que na apresentação e discussão do estudo de caso esses elementos serão analisados quanto à sua contemplação.

\subsection{Vantagens e desvantagens dos tradicionais sistemas de Avaliação de Desempenho}

Nos últimos anos, diversas ferramentas de Avaliação de Desempenho surgiram no contexto científico. Dessa forma, antes de apresentar as vantagens e as desvantagens das ferramentas, é preciso apresentar as principais ferramentas encontradas na literatura. O Quadro 2 apresenta as ferramentas, os autores e uma breve descrição.

Quadro 2 - Principais ferramentas de Avaliação de Desempenho encontradas na literatura (continua)

\begin{tabular}{|c|c|c|}
\hline Ferramenta & Autor & $\begin{array}{c}\text { Característica } \\
\end{array}$ \\
\hline $\begin{array}{c}\text { Performance } \\
\text { Measurement Matrix }\end{array}$ & $\begin{array}{l}\text { (Keegan et } \\
\text { al., 1989) }\end{array}$ & $\begin{array}{l}\text { Ajuda a empresa a definir seus objetivos estratégicos e } \\
\text { traduz esses objetivos em medidas de desempenho. }\end{array}$ \\
\hline $\begin{array}{l}\text { Performance } \\
\text { Pyramid System }\end{array}$ & $\begin{array}{l}\text { (Lynch and } \\
\text { Cross, 1991) }\end{array}$ & $\begin{array}{l}\text { Pirâmide construída em quatro níveis que mostra as } \\
\text { ligações entre a estratégia organizacional com os objetivos } \\
\text { operacionais. }\end{array}$ \\
\hline $\begin{array}{l}\text { Analytic } \\
\text { Hierarchy } \\
\text { Process } \\
(A H P)\end{array}$ & $\begin{array}{l}\text { Saaty, T.L } \\
\text { (1988) }\end{array}$ & $\begin{array}{l}\text { É um método de análise multicriterial baseado em um } \\
\text { processo de ponderação aditiva, no qual os diversos } \\
\text { atributos relevantes são representados através de sua } \\
\text { importância relativa (KIMURA e SUEN, 2003). }\end{array}$ \\
\hline $\begin{array}{c}\text { Performance } \\
\text { Measurement } \\
\text { System for Service } \\
\text { Industries }\end{array}$ & $\begin{array}{l}\text { (Fitzgerald et } \\
\text { al., 1991) }\end{array}$ & $\begin{array}{l}\text { Centrado em seis dimensões que buscam ligar os sistemas } \\
\text { de AD com a estratégia e competitividade. }\end{array}$ \\
\hline
\end{tabular}


Quadro 2 - Principais ferramentas de Avaliação de Desempenho encontradas na literatura

(conclusão)

\begin{tabular}{|c|c|c|}
\hline Balanced Scorecard & $\begin{array}{l}\text { (Kaplan and } \\
\text { Norton, } \\
1992,1996)\end{array}$ & $\begin{array}{l}\text { É baseado em quatro perspectivas (financeira, clientes, } \\
\text { processos internos e aprendizagem e crescimento). Tem } \\
\text { como principal foco ligar a estratégia às atividades } \\
\text { operacionais. }\end{array}$ \\
\hline $\begin{array}{c}\text { Data } \\
\text { Envelopment } \\
\text { Analysis (DEA) }\end{array}$ & $\begin{array}{l}\text { Charnes, } \\
\text { Cooper e } \\
\text { Rhodes, } \\
1978\end{array}$ & $\begin{array}{l}\text { O objetivo é a caracterização de uma medida de eficiência, } \\
\text { que faz com que a decisão fique orientada por um único } \\
\text { indicador construído a partir de várias abordagens de } \\
\text { desempenho diferentes (MACEDO, 2006). }\end{array}$ \\
\hline $\begin{array}{l}\text { Integrated } \\
\text { Performance } \\
\text { Measurement } \\
\text { System }\end{array}$ & $\begin{array}{c}\text { (Bititci et al., } \\
\text { 1997) }\end{array}$ & $\begin{array}{l}\text { Destaca dois principais aspectos da medição de } \\
\text { desempenho: integração das diversas áreas de negócios e a } \\
\text { implantação das políticas e estratégias. Baseia-se em quatro } \\
\text { níveis: corporativo; unidades de negócios; atividades; e } \\
\text { processos). }\end{array}$ \\
\hline $\begin{array}{c}\text { Prêmio Nacional da } \\
\text { Qualidade (PNQ) }\end{array}$ & $\begin{array}{l}\text { Fundação } \\
\text { para o } \\
\text { Prêmio } \\
\text { Nacional da } \\
\text { Qualidade } \\
\text { (1992) }\end{array}$ & $\begin{array}{l}\text { Busca promover amplo entendimento dos requisitos para } \\
\text { alcançar a excelência do desempenho e a melhoria da } \\
\text { competitividade e fomentar um abrangente intercâmbio de } \\
\text { informações sobre métodos e sistemas de gestão que } \\
\text { alcançaram sucesso e sobre os benefícios decorrentes da } \\
\text { utilização dessas estratégias. }\end{array}$ \\
\hline Performance Prism & $\begin{array}{c}\text { (Neely et al., } \\
\text { 2002) }\end{array}$ & $\begin{array}{l}\text { Objetiva medir o desempenho de toda a empresa. Cada face } \\
\text { do modelo prisma corresponde a uma área de análise: a } \\
\text { satisfação dos interessados; estratégias; os processos; } \\
\text { capacidades; e contribuição dos interessados. }\end{array}$ \\
\hline $\begin{array}{l}\text { Integrated } \\
\text { Performance } \\
\text { Measurement for } \\
\text { Small Firms }\end{array}$ & $\begin{array}{c}\text { (Laitinen, } \\
\text { 1996, 2002) }\end{array}$ & $\begin{array}{l}\text { Foco nas Pequenas e Médias Empresas. É baseado em } \\
\text { sete dimensões, duas internas (financeiro e competitividade) } \\
\text { e cinco externas (custos, fatores de produção, atividades, } \\
\text { produtos e receitas). }\end{array}$ \\
\hline
\end{tabular}

Fonte: Garengo, Biazzo e Bititci (2005); Bortoluzzi, Ensslin e Ensslin, (2010b); e Coelho et al., (2008).

Para alcançar o objetivo de elencar vantagens e desvantagens das ferramentas apresentadas, primeiro faz-se necessário definir quais serão os critérios a serem utilizados para realizar essa atividade. Dessa forma, parece ser mais coerente analisar as ferramentas à luz da afiliação teórica de Avaliação de Desempenho adotada pelos autores do presente estudo. Sendo assim, os critérios atendidos pelas ferramentas são considerados como vantagens, e os critérios não atendidos como desvantagens.

Os critérios obtidos por meio da análise da afiliação teórica são: (i) a ferramenta apresenta processo para identificar os objetivos/critérios/indicadores; (ii) a ferramenta realiza a mensuração ordinal e cardinal dos critérios; (iii) a ferramenta integra os critérios para se ter uma avaliação global de desempenho; (iv) a ferramenta disponibiliza um processo estruturado para gerar ações de aperfeiçoamento. 
Com a definição dos critérios, busca-se, no Quadro 3, analisar as ferramentas à luz dos critérios estabelecidos:

Quadro 3 - Vantagens e desvantagens das principais ferramentas de Avaliação de Desempenho

\begin{tabular}{|c|c|c|c|c|}
\hline Ferramenta & Identifica & Mensura & Integra & Aperfeiçoa \\
\hline Performance Measurement Matrix & Parcial & Parcial & Não & Parcial \\
\hline Performance Pyramid System & Parcial & Parcial & Não & Parcial \\
\hline Analytic Hierarchy Process (AHP) & Não & Parcial & Não & Não \\
\hline $\begin{array}{l}\text { Performance Measurement System } \\
\text { for Service Industries }\end{array}$ & Parcial & Parcial & Não & Parcial \\
\hline Balanced Scorecard & Parcial & Parcial & Não & Parcial \\
\hline Data Envelopment Analysis (DEA) & Não & Parcial & Sim & Não \\
\hline $\begin{array}{c}\text { Integrated Performance } \\
\text { Measurement System }\end{array}$ & Parcial & Parcial & Não & Parcial \\
\hline $\begin{array}{l}\text { Prêmio Nacional da Qualidade } \\
\qquad(P N Q)\end{array}$ & Não & Não & Não & Não \\
\hline Performance Prism & Parcial & Parcial & Não & Parcial \\
\hline $\begin{array}{l}\text { Integrated Performance } \\
\text { Measurement for Small Firms }\end{array}$ & Parcial & Parcial & Não & Parcial \\
\hline
\end{tabular}

Fonte: Elaborado pelos autores.

A análise do Quadro 3 permite concluir que, em relação à ferramenta apresentar processo para identificar os objetivos/critérios/indicadores do contexto a partir da percepção do decisor envolvido, nenhuma o faz por meio de um processo estruturado que leva em conta a construção do conhecimento no agente envolvido. Em relação à mensuração, percebe-se que o processo disponibilizado pelas ferramentas também são parciais, pois as que fazem mensuração são somente em uma forma ordinal. No que se refere à integração, a maioria absoluta das ferramentas não disponibiliza um processo para integrar os critérios/indicadores para se ter uma avaliação global de desempenho do contexto em avaliação. E, por fim, a maioria das ferramentas não dispõe de um processo estruturado para gerar ações de aperfeiçoamento para o contexto. 


\subsection{Metodologia Multicritério de Apoio à Decisão Construtivista (MCDA-C)}

A metodologia MCDA-C é uma ferramenta de apoio à decisão que tem sua validade científica comprovada por vários trabalhos científicos publicados em periódicos de destaque no cenário nacional e no internacional, tais como: European Journal of Operational Research; Management Decision; International Journal of Productivity and Performance Management; Pesquisa Operacional; Gestão \& Produção; Revista Brasileira de Gestão de Negócios; Produção Online; Produção, Revista Contemporânea de Contabilidade, entre outras (DUTRA et al., 2009; MORAES et al., 2010; LACERDA, ENSSLIN e ENSSLIN, 2011a; LACERDA, ENSSLIN e ENSSLIN, 2011b; ENSSLIN et al., 2010; BORTOLUZZI, ENSSLIN e ENSSLIN. 2011; VEGINI et al., 2012).

As características que diferenciam a metodologia MCDA-C das demais metodologias de Avaliação de Desempenho podem ser percebidas e analisadas nos seis paradigmas apresentados e discutidos em Lacerda, Ensslin, Ensslin (2009), Ensslin et al. (2010) e Bortoluzzi, Ensslin e Ensslin (2011):

1. Ser construída em forma personalizada para representar os valores e as preferências de seus gestores associados às especificidades do ambiente que se propõe avaliar;

2. Reconhecer que os gestores, mesmo vivenciando o contexto diariamente, não têm claros seus objetivos. O processo utilizado deve reconhecer essas limitações de conhecimento e ajudar aos gestores a construir seu entendimento segundo seus valores e preferências;

3. Os objetivos contidos no modelo de Avaliação de Desempenho são fruto não só dos valores e preferências individuais do gestor, mas também de como este é influenciado pelo contexto onde atua;

4. A construção do modelo de Avaliação de Desempenho requer a participação contínua do gestor para assegurar a construção de seu conhecimento sobre o problema e ter legitimidade;

5. Para dar fundamentação e validade às mensurações realizadas, estas necessitam atender aos requisitos da Teoria da Mensuração; e, 
6. O modelo deve, em cada uma de suas etapas de construção e uso, ter o reconhecimento do gestor quanto à legitimidade do conhecimento construído e sua representação no modelo explícito, assim como garantir que todos os instrumentos utilizados tenham reconhecimento científico.

Esses seis paradigmas representam de uma forma geral as razões pela escolha da metodologia MCDA-C para a construção do modelo de Avaliação de Desempenho apresentado no presente estudo. Adicionalmente acrescentam-se aos seis paradigmas os aspectos de a metodologia MCDA-C ser capaz de: (i) expandir o entendimento do gestor sobre o contexto; (ii) assegurar que o modelo reflete os objetivos do gestor; (iii) permitir uma compreensão da associação dos objetivos estratégicos ao indicador de desempenho; (iv) permitir a compreensão da intensidade com que cada indicador de desempenho participa em cada objetivo; (v) servir de instrumento para comunicar e disseminar o conhecimento do contexto; (vi) ser um processo para gerar ações de aperfeiçoar o desempenho dos objetivos; (vii) ter fundamentação científica validada pela comunidade; e, (viii) ter legitimidade aos olhos do gestor (ENSSLIN et al., 2010).

Como desvantagem cumpre salientar a necessidade de conhecimento do especialista/facilitador sobre a metodologia multicritério bem como o tempo demandado para construção do modelo de Avaliação de Desempenho por meio da metodologia MCDA-C em relação às demais ferramentas de AD (ENSSLIN et al., 2010).

\section{METODOLOGIA DA PESQUISA}

Esta seção tem o objetivo de apresentar: (i) o enquadramento metodológico da pesquisa; e, (ii) os procedimentos para construção do modelo.

\subsection{Enquadramento metodológico}

O estudo se caracteriza como exploratório, pois busca aprofundar o conhecimento sobre as variáveis que causam impacto no desempenho da empresa 
em relação a sua atuação no mercado (GIL, 1999) sendo caracterizado como um estudo de caso na Seprol Computadores e Sistemas Ltda., visto que o estudo de caso permite uma investigação que preserva as características da organização em funcionamento (YIN, 2005).

Em relação à coleta de dados, a pesquisa fez uso de dados primários, porque foram colhidos diretamente em campo por meio de entrevistas (RICHARDSON, 2008); os pesquisadores realizaram diversas visitas à empresa com o objetivo de entrevistar os gestores em todas as fases da estruturação do modelo de avaliação e recomendações.

A pesquisa caracteriza-se como qualitativa, principalmente na fase de estruturação do modelo e recomendação de ações de aperfeiçoamento, e quantitativa, principalmente na fase de avaliação. $O$ instrumento de intervenção escolhido para construção do modelo foi a Metodologia Multicritério de Apoio à Decisão Construtivista (ENSSLIN e VIANNA, 2008).

\subsection{Procedimentos para construção do modelo}

A metodologia se divide em três fases principais: (i) fase da estruturação; (ii) fase da avaliação; e, (iii) fase de elaboração de recomendações.

A fase de estruturação inicia pela contextualização que tem por objetivo identificar o contexto decisório no qual são apresentados os atores, ou seja, aqueles que participam, direta ou indiretamente, do processo em que se realiza a gestão. Os atores desse processo são: o decisor, o facilitador, os intervenientes, e os agidos. $\mathrm{Na}$ sequência, deve-se definir o rótulo para o problema que consiste em elaborar o seu enunciado e deve conter o foco principal do trabalho, indicando o propósito a ser atingido, e finalmente deve ser construído um sumário que contenha as seguintes informações: (i) o problema; (ii) a justificativa da importância do problema; (iii) o objetivo do trabalho; (iv) a proposta para alcançar o objetivo e solucionar o problema; e, (v) o que espera obter ao final do trabalho. Esse conjunto de informações constitui a primeira etapa da fase de estruturação na metodologia MCDA-C denominada Abordagem soft ou Contextualização (ENSSLIN, MONTIBELLER e NORONHA, 2001).

$\mathrm{Na}$ sequência, elabora-se a estrutura hierárquica de valor. Nessa etapa, o 
facilitador estimula o decisor a falar de forma livre sobre o contexto. A partir disso, o facilitador extrai um conjunto de informações correspondentes às preocupações e aos valores do decisor e às propriedades do contexto. Essas informações denominam-se Elementos Primários de Avaliação (EPAs), que representam os aspectos julgados como essenciais pelo decisor e fazem parte do conjunto de elementos que fundamentam as dimensões que ele irá considerar para avaliar o contexto (embora, neste momento ainda vagas). A próxima etapa então consiste em expandir essas informações para transformá-las em conceitos (onde será identificado a direção de preferência que o decisor busca com cada um dos EPAs, bem como a consequência de não alcançar esse propósito). Esses conceitos são agora agrupadas por conteúdo ou por área de preocupação (ENSSLIN et al., 2010). Cada área de preocupação é então composta por um conjunto de conceitos. Para expandir seu entendimento para cada uma dessas é construído uma mapa cognitivo (EDEN et al., 1988). Cada mapa é então desmembrado em seus clusters constituintes, e essa estrutura é transformada em uma Estrutura Hierárquica de Valor (KEENEY, 1992).

A Estrutura Hierárquica de Valor representa em sua parte superior os objetivos estratégicos ou as dimensões estratégicas do decisor para o contexto que, na metodologia MCDA-C, são denominados Pontos de Vista Fundamentais (PVFs). Suas ramificações inferiores explicam quais funções táticas e mais abaixo quais atividades operacionais explicam os objetivos estratégicos. Dessa forma, evidencia o alinhamento entre os objetivos estratégicos e os operacionais, denominados na metodologia MCDA-C de Pontos de Vista Elementares (PVEs). O próximo passo consiste na mensuração desses PVEs. Para tal, escalas ordinais (denominados na metodologia MCDA-C de descritores) são construídas, a partir da explicitação das preferências do decisor. Nessa escala ordinal devem-se especificar os níveis de referência: o nível inferior será denominado por 'Neutro' e o superior por 'Bom' (ENSSLIN et al., 2010). Com essa informação, encerra-se o processo de construção do entendimento qualitativo na metodologia MCDA-C, na fase de estruturação. $O$ aperfeiçoamento do conhecimento agora ocorrerá pela introdução de mais informações que lhe deem mais acuracidade ou precisão e, para isso, é necessário transformar o conhecimento ordinal obtido em cardinal (fase de avaliação). 
A etapa seguinte na Metodologia MCDA-C consiste em transformar as escalas ordinais dos descritores em escalas cardinais (funções de valor). A transformação requer que o decisor forneça a diferença de atratividade entre todos os níveis do descritor. A escala numérica que atender a todas as diferenças de atratividade é uma possível função de valor para o critério ou ponto de vista. Com o propósito de tornar as funções de valor comparáveis, o nível Neutro de cada critério recebe a pontuação '0', e o nível Bom recebe a pontuação '100'. Essa informação permite explicitar o modelo matemático que mensura, local e globalmente, a performance da situação atual do problema e/ou suas variantes (ENSSLIN et al., 2010; VEGINI et al., 2012), sendo necessário apenas a identificação das taxas de compensação dos pontos de vista (critérios). As taxas de compensação são obtidas pela contribuição do ponto de vista ao passar do nível Neutro para o nível Bom. .

O conhecimento construído permite agora visualizar, numérica e graficamente, o perfil da situação atual e das consequências de ações para promover seu aperfeiçoamento. O modelo construído pela metodologia MCDA-C torna possível uma avaliação explícita e fundamentada evidenciando as potencialidades $\mathrm{e}$ as fraquezas e com isso as oportunidades para seu aperfeiçoamento.

O conhecimento gerado permite ao decisor visualizar, gráfica e numericamente, em cada critério, se a performance é "excelente", "normal", ou "comprometedora". Por sua vez, a escala fornece informações sobre quais as performances superiores à atual. Com isso e com o conhecimento adicional do decisor sobre o contexto, ele poderá identificar a ação para melhorar e prever em que nível o contexto ficará caso for implementada. O modelo então informará qual a contribuição no critério e no contexto global. Dessa forma, poderão ser geradas múltiplas ações e ordenadas por ordem de contribuição. Essa fase é denominada fase de recomendações.

\section{ESTUDO DE CASO}

O estudo de caso segue as três fases da metodologia MCDA-C, ou seja, a fase de estruturação, avaliação e recomendações. Cabe salientar que o presente estudo de caso foi realizado na empresa Seprol Computadores e Sistema Ltda., 
sendo que esta empresa foi utilizada como objeto de estudo para a construção de outros modelos de Avaliação de Desempenho com o uso da metodologia MCDA-C (BORTOLUZZI, ENSSLIN e ENSSLIN, 2010c), porém cada modelo foi construído em um contexto diferente (áreas diferentes), o que caracteriza diferenças significativas entre os modelos (originalidade).

\subsection{Fase da Estruturação}

\subsubsection{Contextualização}

A organização desejava um processo que lhe permitisse realizar a gestão da área de mercado de forma clara, fundamentada e participativa, segundo a percepção do Diretor da empresa. As entrevistas iniciais evidenciaram os atores envolvidos na construção do modelo de AD (Quadro 4) bem como as informações de contextualização.

Quadro 4 - Atores envolvidos com o problema de desempenho da área de mercado da empresa

\begin{tabular}{|l|l|}
\hline Decisor & Diretor da Empresa \\
\hline Intervenientes & Acionistas da empresa \\
\hline Facilitador & Autores do trabalho \\
\hline Agidos & Colaboradores; fornecedores; clientes \\
\hline
\end{tabular}

O decisor juntamente com a intervenção dos facilitadores identificaram como: (i) rótulo do problema: Avaliação do Desempenho da área de mercado da Empresa Seprol Computadores e Sistemas Ltda; e, (ii) sumário: O responsável pela área de mercado deseja melhorar a performance segundo sua percepção, mas não tem claro como explicitar esse conhecimento. Esse entendimento é importante para: ser consistente em suas decisões e ações; disseminar o conhecimento daquilo que é importante; poder evidenciar os bons e os maus resultados. Desenvolver o conhecimento do decisor e explicitá-lo na forma de um modelo é o objetivo do decisor. Dados os múltiplos atores com poderes e habilidades distintas, os interesse conflitantes dos envolvidos e as complexidades do contexto, será utilizada a metodologia MCDA-C. Como resultado, espera-se construir conhecimento que permita ter claramente definido o que é importante com escalas para medir seu 
desempenho e taxas que permitam estabelecer uma ordem de contribuição e evidenciem as potencialidades e as fraquezas.

\subsubsection{Estrutura Hierárquica de Valor}

Uma vez legitimada a contextualização, prossegue-se o processo de entrevistas abertas com o decisor. Dessa forma, solicitou-se que o decisor identificasse as preocupações inerentes à área de mercado da empresa. Desse processo, pelas entrevistas com o decisor, surgiram 45 Elementos Primários de Avaliação (EPAs), sendo as dez primeiras listadas no Quadro 5.

Quadro 5 - Exemplos de Elementos Primários de Avaliação (EPAs)

\begin{tabular}{|l|l|}
\hline $\begin{array}{l}1 \text { - Índice aquisição de novos clientes versus } \\
\text { perda de clientes }\end{array}$ & 6 - Concorrência \\
\hline 2 - Tendências do mercado versus crescimento & 7 - Parcerias \\
\hline 3 - Relacionamento com fornecedores & 8 - Logística \\
\hline 4 - Sustentabilidade & 9 - Penetração de mercado \\
\hline 5 - Imagem & 10 - Fortalecimento da marca \\
\hline
\end{tabular}

$\mathrm{Na}$ sequência, foram elaborados, em conjunto com o decisor, os conceitos orientados à ação. Nesse processo, cada EPA passa por uma expansão do conhecimento sobre a preocupação anteriormente elencada no sentido de identificar a direção de preferência de cada EPA e seu oposto psicológico. Os conceitos foram obtidos por entrevistas feitas com o decisor, solicitando-se ao decisor que falasse detalhadamente sobre cada EPA. Seguem, no Quadro 6, exemplos de conceitos orientados à ação, em que as reticências (...) devem ser lidas como "ao invés de" e corresponde ao oposto psicológico. 
Quadro 6 - Exemplos de conceitos orientados à ação

1 - Ter um processo de fidelização de clientes ... perder clientes.

2 - Promover a satisfação do cliente por meio da entrega nos prazos estabelecidos ... ter clientes insatisfeitos.

3 - Garantir parcerias estratégicas para a empresa ... depender de fornecedores normais.

4 - Ter processo para acompanhar a imagem da empresa ... agir intuitivamente.

5 - Ter processo para permitir o fortalecimento da marca ... permitir o enfraquecimento da marca.

6 - Ter um processo para identificar a participação no mercado ... não saber onde a empresa atua.

7 - Ter processo para pró-ativamente mitigar os riscos ... agir emergencialmente.

8 - Ter um processo para acompanhar as tendências de mercado ... Desconhecer

9 - Ter processo para garantir a sobrevivência da empresa no longo prazo ... não garantir a continuidade da empresa.

10- Ter processo de acompanhamento da concorrência ... agir sem informações.

Em seguida, identificados os EPAs e da construção dos conceitos orientados à ação, compreendeu-se melhor as preocupações do decisor em relação aos aspectos que causam impacto no desempenho. Assim foi possível, em conjunto com o decisor, elaborar as áreas de preocupação. Seguem, na Figura 1, as áreas de preocupações para a área de mercado:

Figura 1 - Agrupamentos dos Conceitos em Áreas de Preocupação nos PVFs área de Mercado

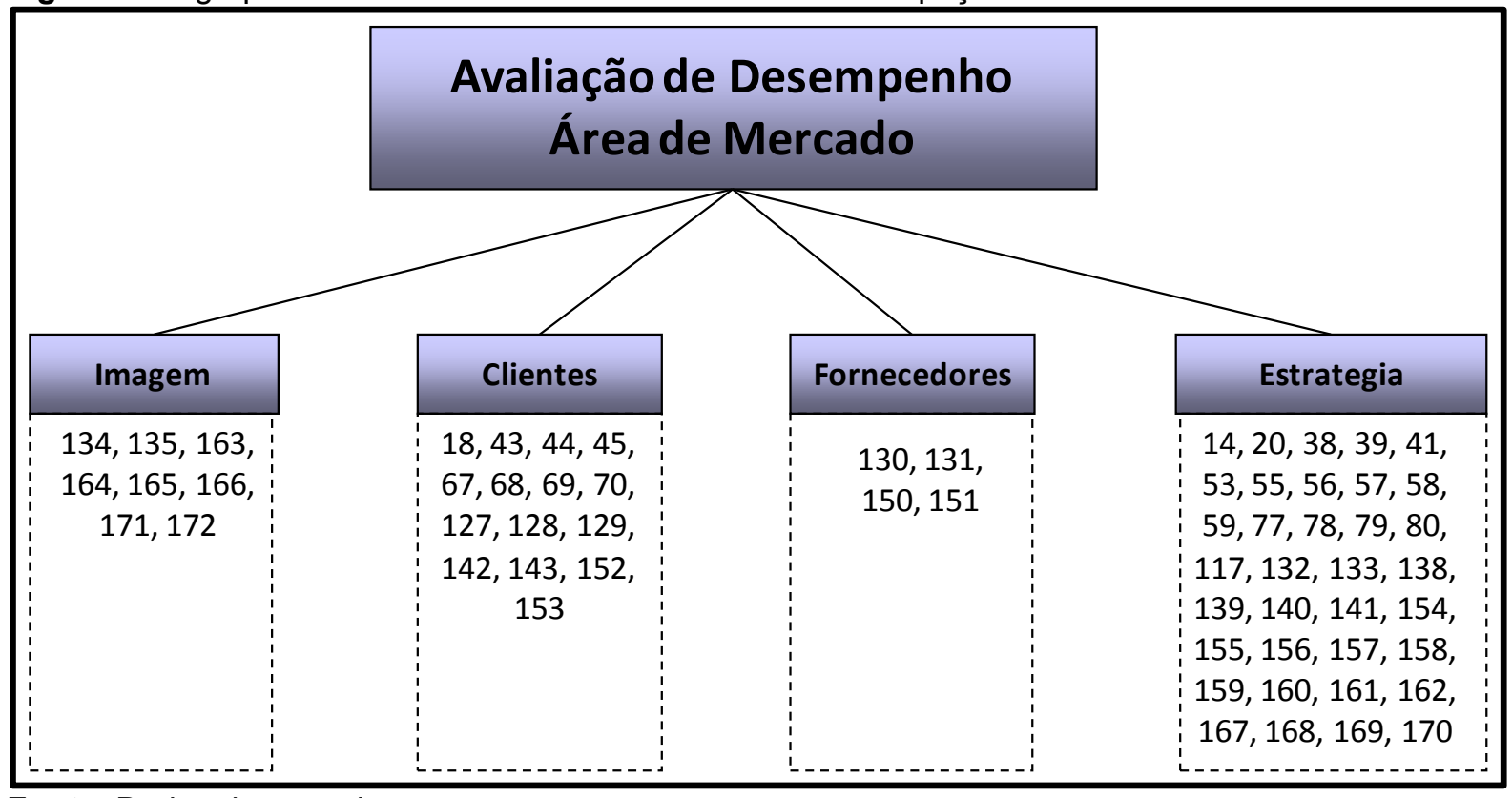

Fonte: Dados da pesquisa.

A próxima etapa da fase de estruturação consiste em elaborar os Mapas de Relações Meios-Fins e, em seguida, agrupá-los em Clusters. Na Figura 2, apresenta-se o mapa para a dimensão ou área de preocupação "Imagem". 
Figura 2 - Mapa de Relações Meios-Fins da dimensão Imagem

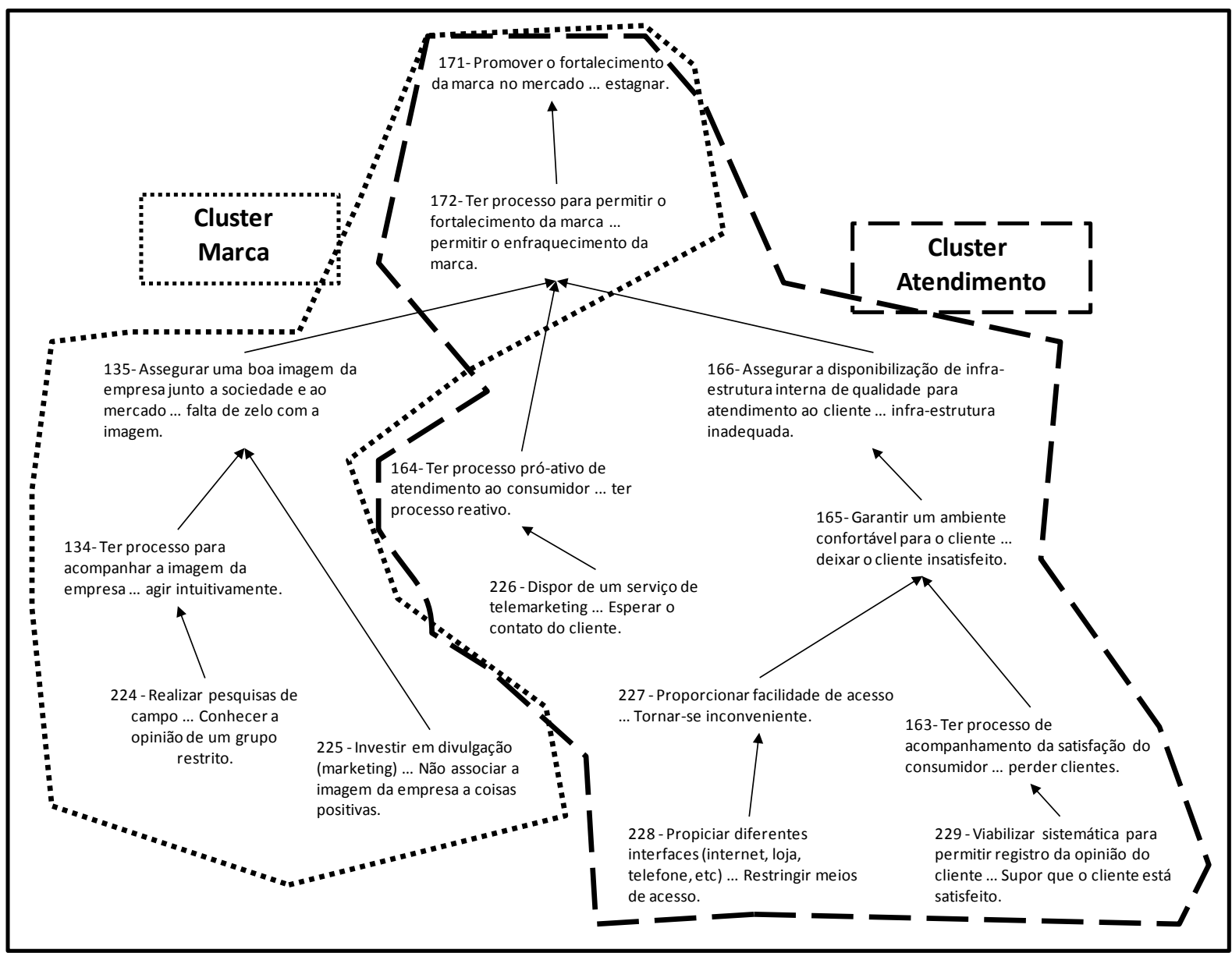

Fonte: Dados da pesquisa.

Percebe-se que o mapa da dimensão "Imagem" é respondido por dois clusters: o primeiro relacionado aos aspectos de "Marca"; o segundo relacionado aos aspectos de "Atendimento". Na sequência, foi feita a transição do Mapa de Relações Meios-Fins para a Estrutura Hierárquica de Valor e construídos os Descritores. Demonstra-se a estrutura hierárquica de valor e os descritores para o PVF "Imagem": 
Figura 3 - Estrutura Hierárquica de Valor para o PVF "Imagem"

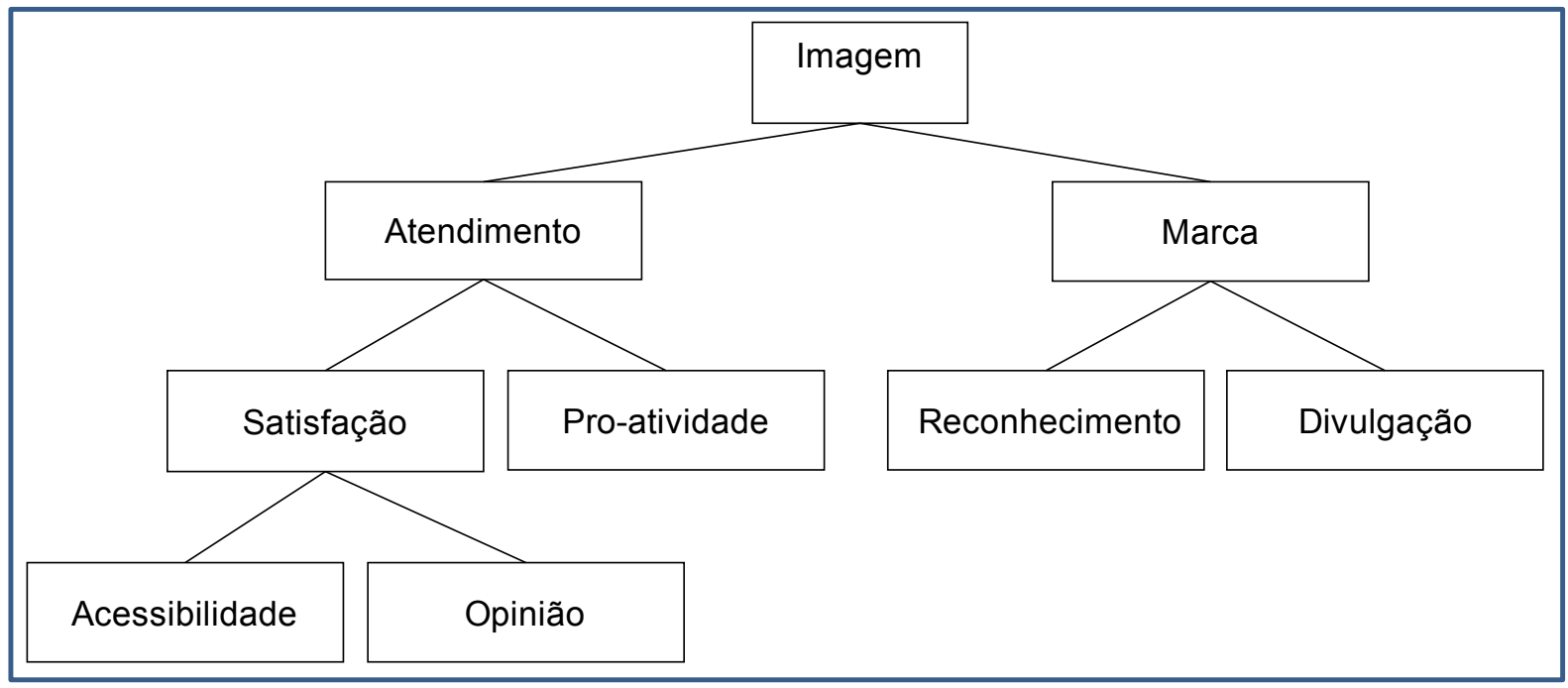

\subsubsection{Construção dos Descritores}

Uma vez explicitados os PVEs que compõem o PVF Imagem, foi dado início à construção dos descritores. Dessa forma, emergiram os descritores apresentados na Figura 4: Estrutura Hierárquica de Valor e Descritores do PVF Imagem. Nessa representação, já foram incorporados os níveis Neutro e Bom. 
Figura 4 - Estrutura Hierárquica de Valor e Descritores do PVF Imagem

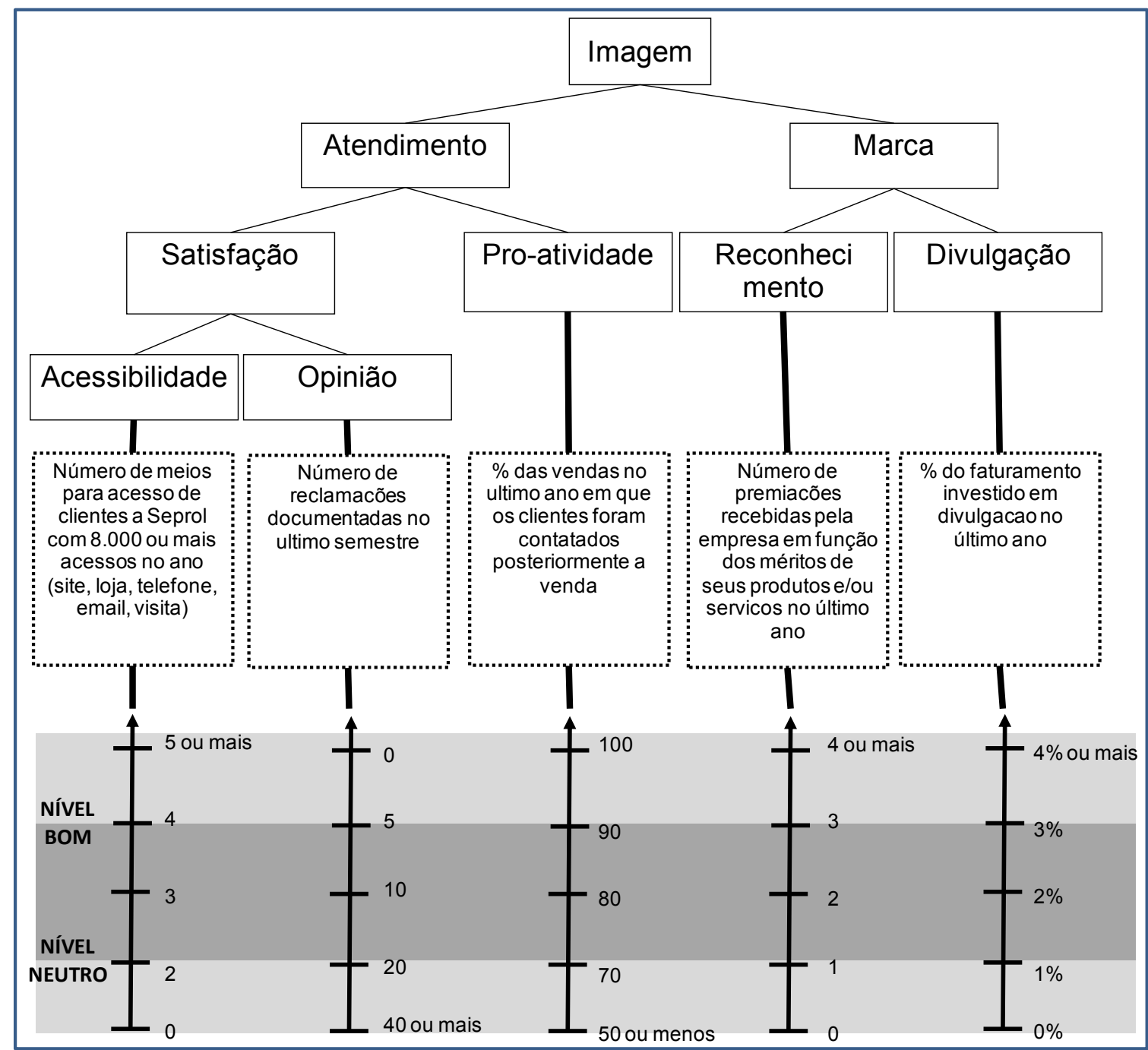

Fonte: Dados da pesquisa.

O modelo desenvolvido contempla, em todas as etapas da estruturação, o fato de levar em consideração os aspectos intangíveis, que são considerados, na literatura, como essências no atual contexto em que as empresas atuam, visto que os aspectos somente financeiros já não respondem adequadamente às necessidades dos gestores (HAN e HAN, 2004; KAPLAN e NORTON, 2000). Adicionalmente, o modelo desenvolvido contempla, na etapa de construção dos Mapas de Relações Meios-Fins, a possibilidade de verificar o alinhamento entre os objetivos operacionais com os objetivos considerados pela organização como estratégicos, pois, segundo os trabalhos pesquisados que compõem a revisão da literatura, esses aspectos que ligam a estratégia ao operacional e entendem as ligações existentes são de fundamental importância para o sucesso na implantação 
de um sistema de Avaliação de Desempenho (KAPLAN e NORTON, 2000; YEO, 2003; GARENGO, BIAZZO e BITITCI, 2005; PUNNIYAMOORTHY e MURALI, 2008).

\subsection{Fase da Avaliação}

\subsubsection{Transformação dos Descritores (indicadores) em Funções de Valor e Determinação das Taxas de Compensação}

A fase de avaliação é composta pela realização das seguintes etapas: (i) construção das Funções de Valor para cada Ponto de Vista Elementar (PVE); (ii) determinação das Taxas de Compensação; e, (iii) realização da Avaliação Global e Perfil de Impacto do status quo.

A primeira etapa consiste em transformar as escalas ordinais em escalas cardinais, ou seja, identificar por meio do julgamento dos decisores a diferença de atratividade entre os níveis dos descritores. Essa etapa realiza-se com a ajuda do software Macbeth, em que se constrói uma função de valor para cada descritor. Salienta-se que as funções de valor são estabelecidas com base nos níveis de ancoragem, sendo que o nível Bom foi ancorado em 100 pontos e o nível Neutro em 0 ponto. Dessa forma, os níveis Bom e Neutro terão o mesmo grau de atratividade para todos os descritores e igual pontuação numérica para todas as funções de valor. Com a finalidade de ilustrar o processo de transformação das escalas ordinais em escalas cardinais, escolheu-se o descritor "Pro-atividade", conforme consta na Figura 5. 
Figura 5 - lustração da transformação da escala ordinal em escala cardinal

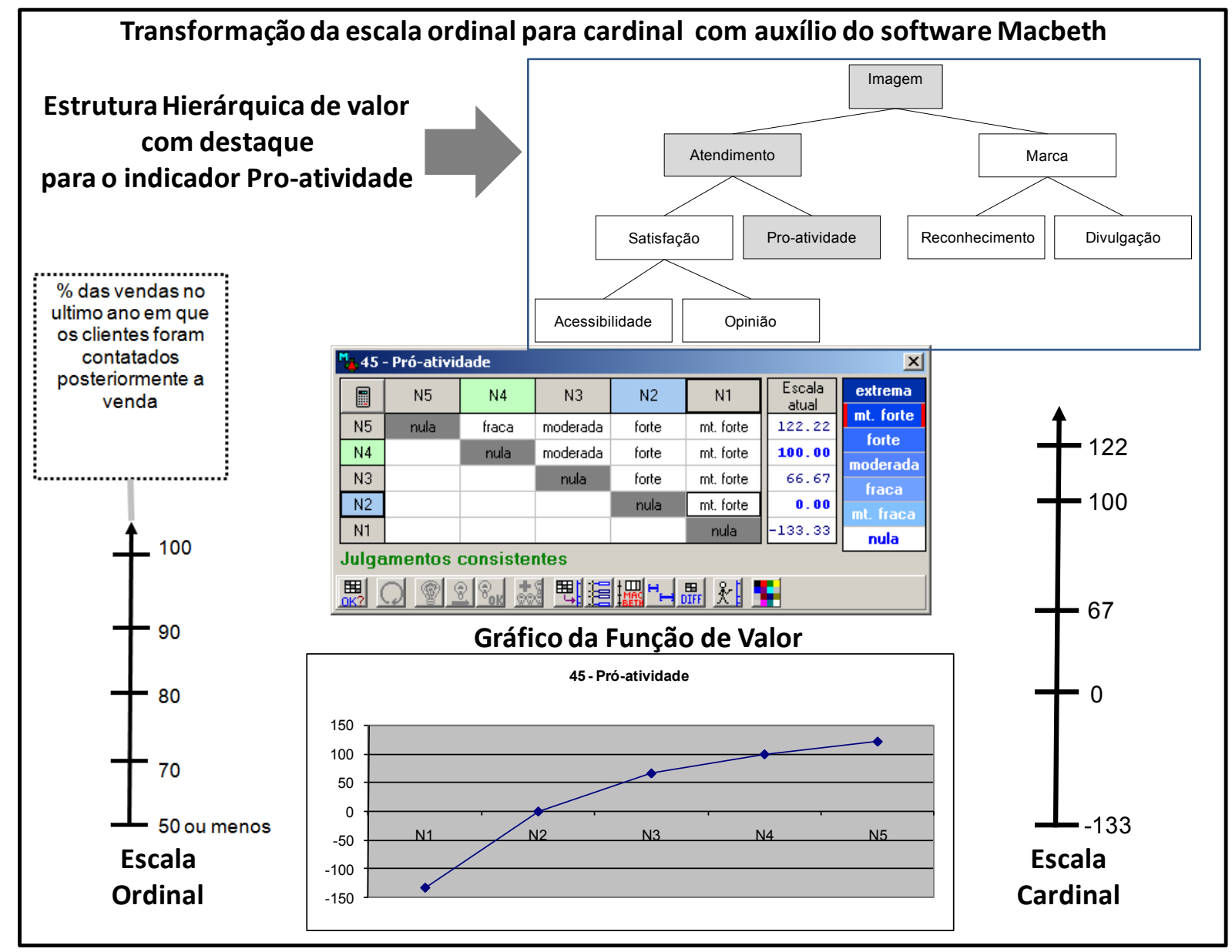

Fonte: Dados da pesquisa

Com base na identificação das escalas cardinais, o decisor possui o entendimento da diferença de atratividade entre passar de um nível de impacto a outro em cada indicador de desempenho. Entretanto, somente essas informações não são suficientes para se realizar a Avaliação Global de Desempenho. Dessa forma, buscou-se definir as Taxas de Compensação por meio da percepção do decisor, conforme é abordado a seguir.

As Taxas de Compensação irão permitir a agregação aditiva dos critérios (indicadores), possibilitando a Avaliação Global de Desempenho da área de mercado da empresa. Para se calcularem as Taxas de Compensação, criam-se ações potenciais fictícias que representam a contribuição da passagem do nível Neutro para a do nível Bom, em cada um dos critérios que se desejam determinar as taxas, bem como uma ação de referência com desempenho Neutro em todos os Pontos de Vista, conforme apresentado na Figura 6: 
Figura 6 - Alternativas potenciais para determinar as taxas de substituição com a indicação dos respectivos níveis Bom e Neutro
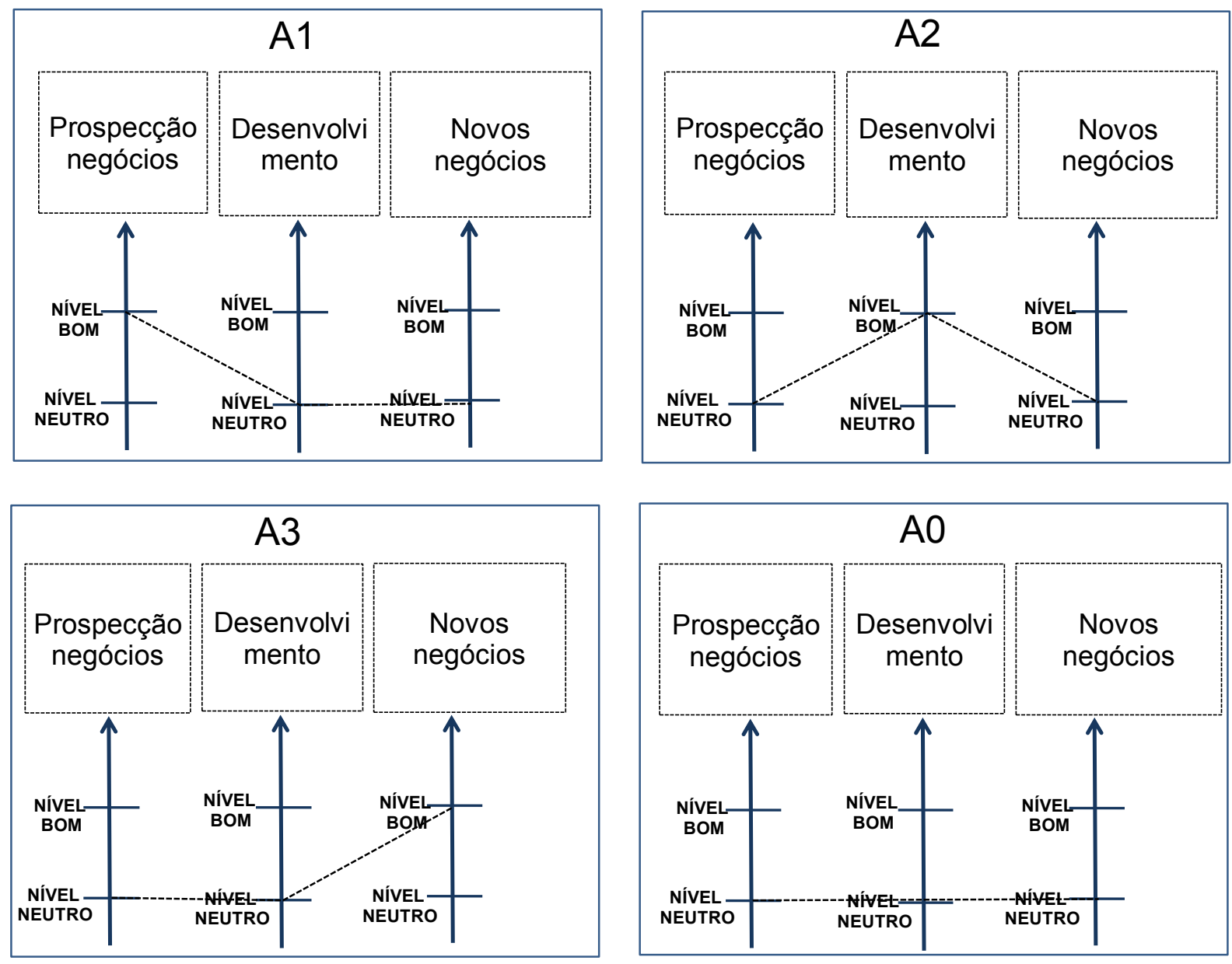

O primeiro passo para calcular as taxas de compensação consiste em hierarquizar as alternativas por meio da matriz de Roberts (1979), que solicita ao decisor a preferência entre as alternativas.

Figura 7 - Matriz de Roberts da comparação das alternativas representando a contribuição de passar do nível Neutro para o Bom em cada Ponto de Vista considerado

\begin{tabular}{|c|c|c|c|c|c|c|}
\hline & $\mathrm{A} 1$ & $\mathrm{~A} 2$ & $\mathrm{~A} 3$ & $\mathrm{~A} 0$ & SOMA & ORDEM \\
\hline $\mathrm{A} 1$ & & 0 & 0 & 1 & 1 & $3^{\circ}$ \\
\hline $\mathrm{A} 2$ & 1 & & 0 & 1 & 2 & $2^{\circ}$ \\
\hline $\mathrm{A} 3$ & 1 & 1 & & 1 & 3 & $1^{\circ}$ \\
\hline $\mathrm{A} 0$ & 0 & 0 & 0 & & 0 & $4^{\circ}$ \\
\hline
\end{tabular}


$\mathrm{Na}$ sequência, inserem-se as informações relacionadas na hierarquização realizada anteriormente e solicita-se ao decisor o julgamento par a par das ações potenciais. Esse procedimento pode ser verificado na Figura 8:

Figura 8 - Taxas de substituição geradas pelo software M-MACBETH da comparação da diferença de atratividade entre as alternativas

\begin{tabular}{|c|c|c|c|c|c|}
\hline & A3 & A2 & A1 & A0 & $\begin{array}{l}\text { ESCALA } \\
\text { ATUAL }\end{array}$ \\
\hline A3 & & muito fraca & fraca & extrema, muito forte, fraca & 50.00 \\
\hline A2 & & & fraca & extrema, muito forte, fraca & 37.00 \\
\hline A1 & & & & extrema, muito forte, fraca & 13.00 \\
\hline AO & & & & & 0.00 \\
\hline
\end{tabular}

A Figura 9 apresenta a modelo de avaliação para o PVF Imagem com taxas de substituição e Perfil do status quo. 
Figura 9 - Estrutura Hierárquica de Valor e o comportamento gráfico do Status Quo do PVF Imagem

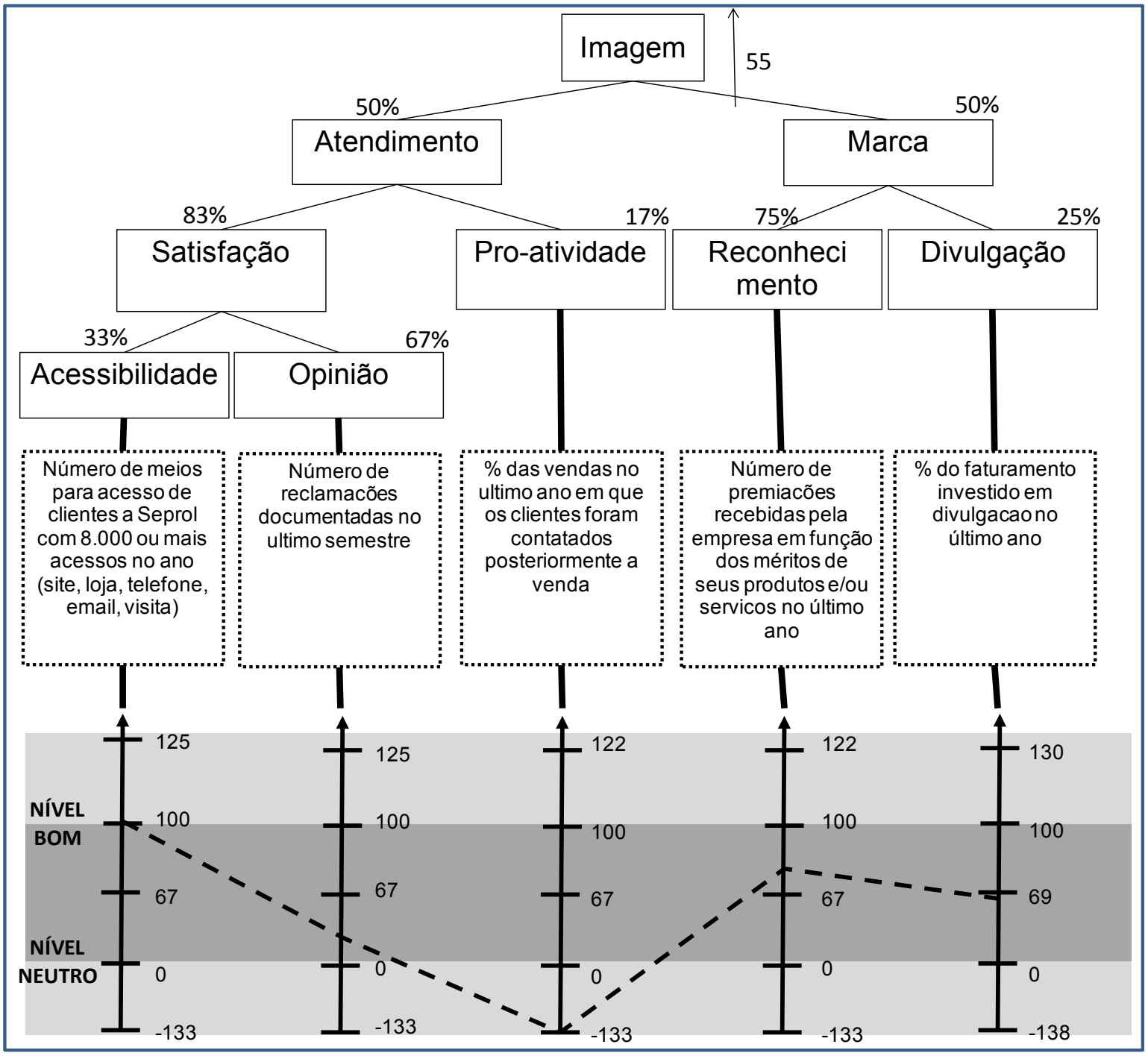

\subsubsection{Diagnóstico ou Perfil da Situação Atual - Status Quo}

\section{Avaliação Global, Perfil de Impacto e Avaliação do Status Quo}

A situação atual apresentou uma performance de 62 pontos para a escala construída, e foi considerada como competitiva segundo a percepção do decisor. A avaliação e a representação gráfica estão apresentadas na Figura 10, que evidencia dessa forma as consequências da situação atual naqueles aspectos julgados pelo decisor como necessários e suficientes para avaliar a atuação da empresa no mercado. 
Figura 10 - Perfil de Impacto do status quo

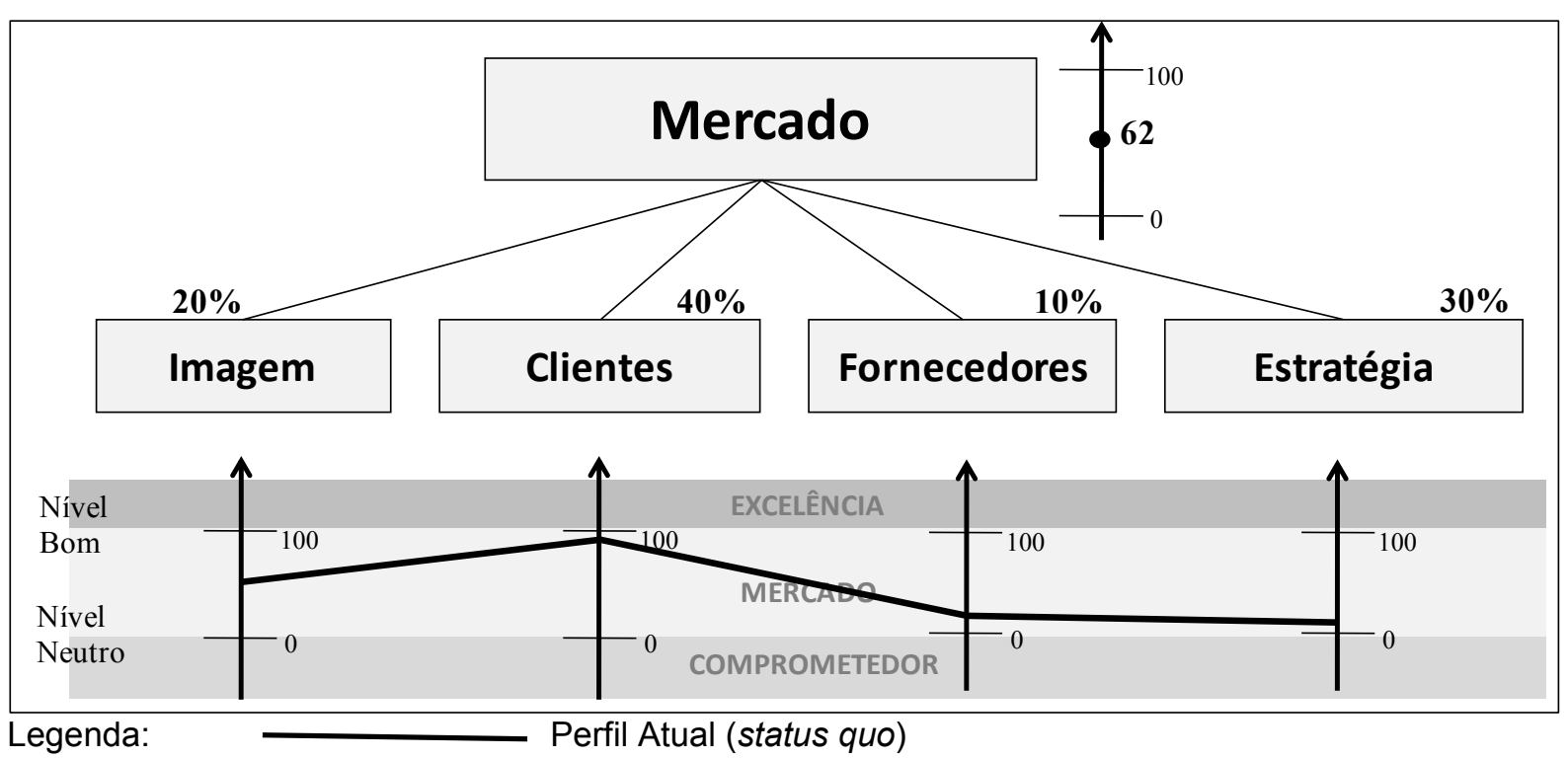

Fonte: Dados da pesquisa.

Apresenta-se, na Figura 10, a Avaliação de Desempenho atual da área de mercado da empresa Seprol Computadores e Sistemas Ltda., e também o Perfil de Impacto do status quo.

A avaliação global de 62 pontos é formada pela soma de cada PVF. Dessa forma, a equação global do modelo para os PVFs é demonstrada abaixo:

Equação 1 - Equação para Avaliação Global de Desempenho de uma alternativa genérica $\alpha$.

$V(\alpha)=0,20 * V_{P V F 1}(\alpha)+0,40 * V_{P V F 2}(\alpha)+0,10 * V_{P V F 3}(\alpha)+0,30 * V_{P V F 4}(\alpha)$

Fonte: Dados da pesquisa.

Assim, para cada PVF, ter-se-á um modelo na forma da Equação 2.

Equação 2 - Equação genérica para Avaliação Global de Desempenho

$$
V_{P V F_{k}}(a)=\sum_{i=1}^{n_{k}} w_{i, k} \bullet v_{i, k}(a)
$$

Fonte: Dados da pesquisa.

Em que:

$V_{P V F_{k}}(a)$ : valor global da ação a do $\mathrm{PVF}_{\mathrm{k}}$, para $\mathrm{k}=1, \ldots \mathrm{m}$; 
$v_{i, k}(a)$ : valor parcial da ação a no critério $\mathrm{i}, \mathrm{i}=1, \ldots \mathrm{n}$, do $\mathrm{PVF}_{\mathrm{k}}$, para $\mathrm{k}=1, \ldots \mathrm{m}$;

a: ação a;

$w_{i, k}:$ taxas de substituição do critério $\mathrm{i}, \mathrm{i}=1, \ldots \mathrm{n}$, do $\operatorname{PVF}_{\mathrm{k}}$, para $\mathrm{k}=1, \ldots \mathrm{m}$;

$\mathrm{n}_{\mathrm{k}}$ : número de critérios do $\mathrm{PVF}_{\mathrm{k}}$, para $\mathrm{k}=1, \ldots \mathrm{m}$;

m: número de PVFs do modelo.

Para o $\mathrm{PVF}_{3}$ utilizado nas ilustrações, ter-se-ia:

Equação 3 - Ilustração de equação para o Ponto de Vista Fundamental (PVF) 1.

$$
\begin{aligned}
& V_{P V F 1}(\alpha)= \\
& 0,50\left\{0,83\left[0,33 * V_{\text {Acessibilidade }}+0,67 * V_{\text {Opinião }}\right]+0,17 * V_{\text {Pro-atividade }}\right\}+ \\
& 0,50\left\{0,75 * V_{\text {Reconhecimento }}+0,25 * V_{\text {Divulgação }}\right\}
\end{aligned}
$$

Fonte: Dados da pesquisa

Nas etapas da fase de avaliação, levaram-se em consideração as particularidades da área de mercado da empresa Seprol Computadores e Sistemas Ltda., por meio da percepção do decisor da empresa (GOLDSZMIDT e PROFETA, 2004; WERNKE e LEMBECK, 2004; DUTRA, 2005; CARPES, ENSSLIN e ENSSLIN, 2006).

\subsection{Fase de Recomendações}

A fase de recomendações permite construir estratégias que possibilitem melhorar o desempenho da empresa. Nesse sentido, pela interação entre decisor e facilitador e pela leitura do status quo elaborado na fase de avaliação, decidiu-se criar estratégias que possibilitem elevar o desempenho da área de mercado da empresa.

Nesse contexto, identificaram-se os objetivos táticos (gerenciais) e os objetivos operacionais que estão com desempenho abaixo do nível Neutro e também aqueles em que o desempenho está no nível de mercado, mas que o decisor entende que deveriam ser elaboradas estratégias de melhoria. Buscou-se também priorizar os objetivos com maior contribuição no desempenho global por meio das taxas de compensação. 
Com o sucesso na implementação da estratégia, a empresa Seprol Computadores e Sistemas Ltda. teria melhor desempenho na área de mercado, em que o desempenho global passaria de 62 pontos para 76 pontos, como pode ser visualizado na Figura 11:

Figura 11 - Perfil de Impacto do status quo da área de mercado e Perfil de Impacto após implantação da estratégia

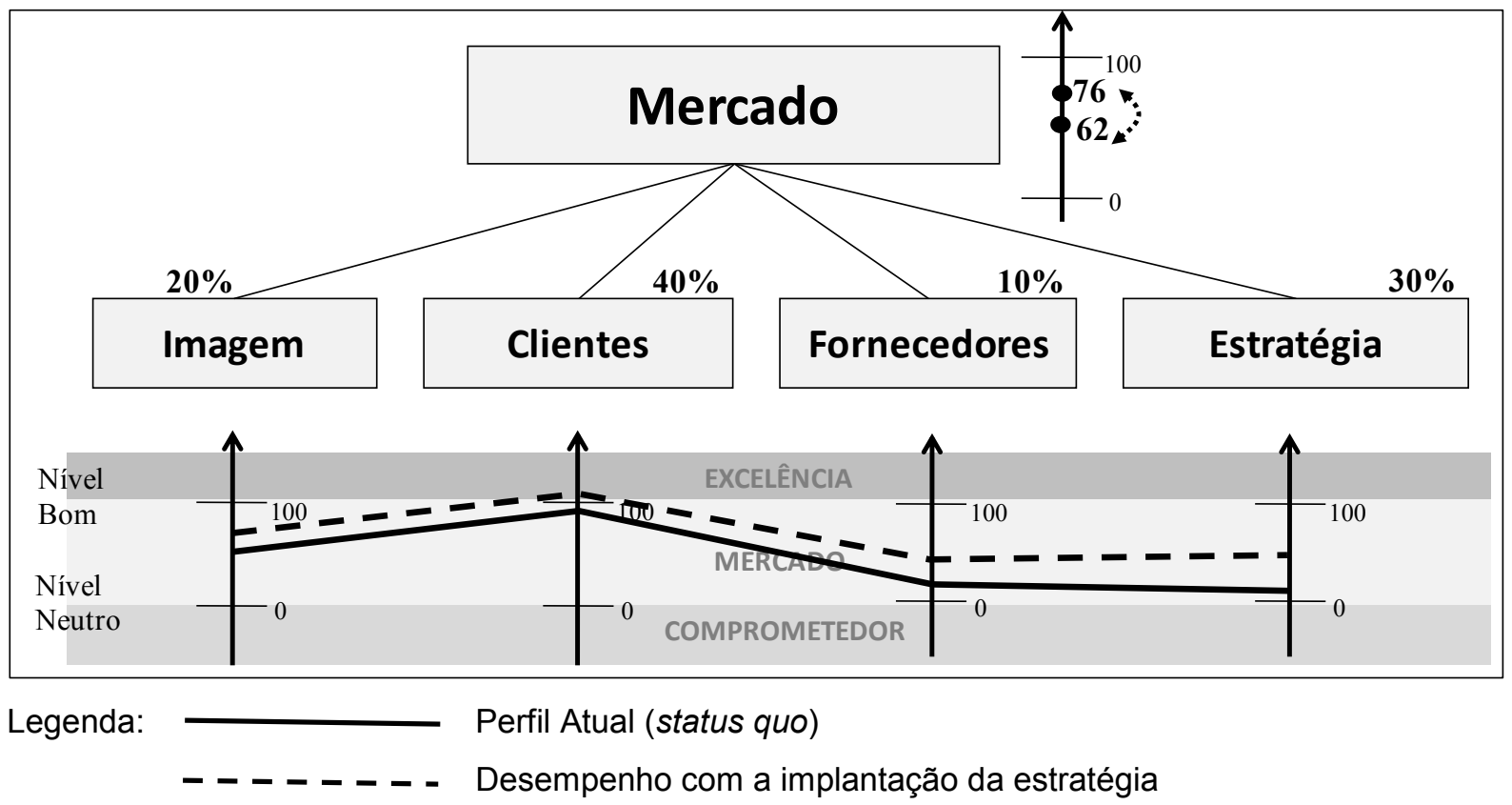

Fonte: Dados da pesquisa.

Usa-se o modelo de Avaliação de Desempenho para elaborar estratégias de melhoria e recomendações para que a empresa possa conseguir um desempenho superior. Isso pode ser realizado de várias formas como: (i) identificar o desempenho de cada descritor (indicador) para conhecer o desempenho específico em determinada variável; (ii) estabelecer estratégias diferentes para identificar o impacto na avaliação global de desempenho; (iii) analisar a relação custo versus benefício na implementação de uma estratégia; (iv) estabelecer prioridades nas estratégias e ações que se pretende implementar por meio dos objetivos com maior grau de contribuição (taxas de compensação); e, (v) avaliar o desempenho em cada nível (estratégico, tático e operacional).

Salienta-se que a fase de recomendações está alinhada com a afiliação teórica da Avaliação de Desempenho Organizacional, pois consegue conduzir o gerenciamento do desempenho nos níveis estratégico, tático e operacional, com 
base nas potencialidades e fragilidades e sugerir ações de aperfeiçoamento (ENSSLIN et al., 2010)

\section{CONSIDERAÇÕES FINAIS}

O artigo teve como preocupação principal responder à seguinte pergunta de pesquisa: Quais indicadores devem ser considerados em um modelo que pretende avaliar as particularidades do desempenho da área de mercado de uma empresa de informática? A pergunta foi respondida à medida que se identificaram 21 indicadores de desempenho para avaliar a atuação da empresa Seprol Computadores e Sistemas Ltda. em relação ao mercado de atuação. Nesse sentido, para fins de ilustração, apresentam-se alguns indicadores de desempenho construído: (i) \% das vendas no último ano em que os clientes foram contatados após a venda - esse indicador avalia a pro-atividade da empresa; (ii) número de premiações recebidas pela empresa em função dos méritos de seus produtos e/ou serviços no último ano o objetivo desse indicador é avaliar o reconhecimento dos produtos da empresa no mercado; (iii) \% do faturamento investido em divulgação no último ano - esse indicador avalia o investimento da empresa na divulgação de seus produtos e serviços; (iv) \% dos atendimentos a clientes em que houve a necessidade de retorno - esse indicador mede a eficiência da assistência técnica; (v) quantidade de horas despendidas na prospecção de novos negócios no trimestre - esse indicador mede o esforço da empresa para se manter competitiva no longo prazo; e (vi) \% dos vendedores que alocaram $90 \%$ ou mais de seu tempo em contato direto com os clientes - esse indicador mede o foco da empresa no cliente. Cabe ressaltar que esses indicadores foram construídos em conjunto com o decisor para avaliar os objetivos por ele estabelecidos.

O objetivo do trabalho consistiu em construir um modelo de Avaliação de Desempenho para a área de mercado da empresa Seprol Computadores e Sistemas Ltda. Esse objetivo foi atingido porque se conseguiu construir um modelo para avaliar as particularidades da empresa no que diz respeito à sua atuação no mercado. Cabe ressaltar que o modelo foi organizado em forma de Estrutura Hierárquica de Valor, que permite visualizar o desempenho nos níveis estratégico, 
tático e operacional. Dessa forma, o gestor consegue identificar as ações que devem ser implementadas para melhorar o desempenho nos objetivos colocados.

Após responder à pergunta da pesquisa e atender ao objetivo geral, tem-se como propósito explicitar o atendimento aos os objetivos específicos da pesquisa: (i) explicitar os objetivos da área de mercado que o decisor deseja maximizar - esse primeiro objetivo específico foi atendido à medida que se identificaram os Elementos Primários de Avaliação (Quadro 5) e, na sequência, os conceitos orientados à ação (Quadro 6) e também por meio dos conceitos que surgiram na construção dos mapas cognitivos (Figura 2); (ii) identificar a relação de causa e efeito entre os objetivos - esse segundo objetivo específico foi alcançado por meio dos mapas cognitivos (Figura 2); (iii) organizar os objetivos em uma Estrutura Hierárquica de Valor - o terceiro objetivo específico foi atingido por meio do agrupamento dos conceitos em área de preocupação (Figura 1) e, na sequência, pela transição dos mapas cognitivos para o restante da Estrutura Hierárquica de Valor (Figura 4); (iv) construir escalas ordinais e cardinais para os indicadores identificados - esse objetivo específico foi alcançado pela construção de 21 indicadores de desempenho para avaliar os objetivos operacionais da empresa em relação ao mercado e depois pela transformação das escalas ordinais em cardinais (Figuras 4, 5 e 9); (v) traçar o perfil de desempenho e avaliar o desempenho local e global - esse objetivo específico foi alcançado (Figuras 9 e 10); e, (vi) criar estratégias para melhorar o desempenho da área de mercado - esse último objetivo específico foi atingido por meio da elaboração de estratégias de melhoria para os objetivos levantados (Figura 11).

Em suma, o trabalho possibilitou construir um modelo de Avaliação de Desempenho para a área de mercado da empresa por meio da percepção do decisor e das particularidades da organização. Destaca-se que a área de mercado da empresa é respondida por quatro grandes dimensões: imagem; clientes; fornecedores e estratégias.

Ressalta-se que o modelo atendeu aos seguintes elementos citados na literatura: (i) avaliar os aspectos intangíveis, tais como: imagem, atendimento, marca, parcerias, credibilidade, etc.; (ii) realizar a avaliação global de desempenho (62 pontos em uma escala de 0 a 100 pontos); e, (iii) identificar o alinhamento entre os objetivos operacionais e os objetivos estratégicos, conforme explicitado na Figura 
9, em que acessibilidade e opinião (critérios operacionais) respondem pela satisfação dos clientes (critério tático), que por sua vez somado ao aspecto próatividade respondem pelo atendimento (critério estratégico).

Salienta-se que o modelo desenvolvido está alinhado à afiliação teórica do conceito de Avaliação de Desempenho Organizacional adotada para este trabalho, ou seja, o modelo de Avaliação de Desempenho permite construir, fixar e disseminar conhecimentos pela identificação, organização, mensuração e integração dos aspectos de um determinado contexto, julgados relevantes para medir e gerenciar o desempenho dos objetivos estratégicos da organização.

Como limitações da pesquisa, apontam-se os seguintes aspectos: (i) o modelo tem legitimidade para a empresa estudada; e, (ii) as estratégias elaboradas na fase de recomendações foram simulações. Nesse sentido, sugere-se, para futuras pesquisas, que a proposta de Avaliação de Desempenho deste estudo seja feita em outras empresas e com outros decisores. Sugere-se também que outras pesquisas consigam acompanhar o resultado da implantação do modelo na empresa e verificar a implantação da estratégia e os resultados alcançados.

\section{REFERÊNCIAS}

ANTUNES, M. T. P.; MARTINS, E. Capital intelectual: seu entendimento e seus impactos no desempenho de grandes empresas brasileiras. BASE - Revista de Administração e Contabilidade da Unisinos, v. 4, n. 1, p. 5-21, 2007.

ASSAF NETO, A. Finanças corporativas e valor. São Paulo: Atlas, 2003.

BANA e COSTA, C. A.; ENSSLIN, L.; CORREA, E. C.; VANSNICK, J.-C. Decision Support Systems in action: Integrated application in a multicriteria decision aid process. European Journal of Operational Research, v. 113, n. 2, p. 315-335, 1999.

BARBOSA, J. G. P.; GOMES, J. S. Um estudo exploratório do controle gerencial de ativos e recursos intangíveis em empresas brasileiras. RAC, v. 6, n. 2, p. 29-48, 2002.

BITITCI, U.S.; CARRIE, A.S.; MCDEVITT, L. Integrated performance measurement systems: a development guide. International journal operations \& Production management, v.17, n.5, p.522-534, 1997.

BORTOLUZZI, S. C.; ENSSLIN, S. R.; ENSSLIN, L. Avaliação de desempenho dos aspectos tangíveis e intangíveis da área de mercado: estudo de caso em uma média 
empresa industrial. RBGN Revista Brasileira de Gestão de Negócios, v. 12, n. 37, p. 425-446, 2010a.

BORTOLUZZI, S. C.; ENSSLIN, S. R.; ENSSLIN, L. Congruências e divergências na avaliação de desempenho organizacional em pesquisas publicadas em periódicos nacionais e internacionais. Ciências Sociais em Perspectiva, v. 9, p. 75-95, 2010b.

BORTOLUZZI, S. C.; ENSSLIN, S. R.; ENSSLIN, L. Construção de um modelo de avaliação de desempenho para a gestão financeira de uma empresa de informática. CAP-Accounting and Management, v. 4, n. 4, p. 12-22, 2010c.

BORTOLUZZI, S. C; ENSSLIN, S.R; ENSSLIN, L; VICENTE, E.F.R. Práticas de avaliação de desempenho organizacional em pequenas e médias empresas: investigação em uma empresa de porte médio do ramo moveleiro. Revista Produção online, v. 10, n. 3, p. 551-576, 2010.

BORTOLUZZI, S. C.; ENSSLIN, S. R.; ENSSLIN, L. Avaliação de desempenho multicritério como apoio à gestão de empresas: Aplicação em uma empresa de serviços. Gestão \& Produção, v. 18, n. 3, p. 633-650, 2011.

CARPES, M. M. M.; ENSSLIN, L.; ENSSLIN, S. R. Avaliação do desempenho das práticas de responsabilidade social na gestão organizacional por meio da metodologia MCDA-Construtivista: uma abordagem aos modelos já existentes.

Revista Alcance, v.13. n.1, p. 91-112, 2006.

CATELLI, Armando (coordenador). Controladoria: uma abordagem da gestão econômica - GECON. São Paulo: Atlas, 1999.

CHARNES, A., W.W. COOPER, AND E. RHODES. Measuring the efficiency of decision making units, European Journal of Operational Research 2, 429-444, 1978.

CHENHALL, R. H.; LANGFIELD-SMITH, K. Multiple Perspectives of Performance Measures. European Management Journal, v. 25, n. 4, p. 266-282, 2007.

COELHO, A. L. A. L.; COELHO, C.; NASCIMENTO, S.; BORTOLUZZI, S. C.; ENSSLIN, L. Investigação na produção científica das principais ferramentas gerenciais sob a perspectiva da avaliação de desempenho organizacional. Congresso Brasileiro de Custos. Curitiba-PR 2008.

CORREAA, H. L.; HOURNEAUX JUNIOR, F. Sistemas de mensuração e avaliação de desempenho organizacional: estudo de casos no setor químico no Brasil. Revista Contabilidade e Finanças USP, v. 19, n. 48, p. 50-64, 2008.

DAFT, R. L.; MARCIC, D. Understanding management. 4. ed. Mason: Thomson South Western, 2004. 
DUTRA, A. Metodologias para avaliar o desempenho organizacional: revisão e proposta de uma abordagem multicritério. Revista Contemporânea de Contabilidade, v. 2, n. 1, 2005.

DUTRA, A., ENSSLIN, S., ENSSLIN, L., ANDRADE DE LIMA, M.. A incorporação da dimensão integrativa nos processos de avaliação do desempenho organizacional: um estudo de caso. Revista Contemporânea de Contabilidade, v.6, n.11, 2009.

EDEN, C. Cognitive mapping. European Journal of Operational Research, v. 36, p. 1-13, 1988.

EDVINSSON, L; MALONE, M.S. Capital intelectual: descobrindo o valor real de sua empresa pela identificação de seus valores internos. São Paulo: Makron Books, 1998.

ENSSLIN, L.; GIFFHORN, E.; ENSSLIN, S. R.; PETRI, S. M.; VIANNA, W. B. Avaliação do desempenho de empresas terceirizadas com o uso da metodologia multicritério de apoio à decisão-construtivista. Revista Pesquisa Operacional, v.30, n. 1, p. $125-152,2010$.

ENSSLIN, L.; ENSSLIN, S. R.; PACHECO, G. C. Um estudo sobre segurança em estádios de futebol baseado na análise bibliométrica da literatura internacional.

Perspect. ciênc. inf., Belo Horizonte, v. 17, n. 2, p. 71-91, 2012.

ENSSLIN, L.; MONTIBELLER, G. N.; NORONHA, S. M. Apoio à decisão: metodologias para estruturação de problemas e avaliação multicritério de alternativas. Florianópolis: Ed. Insular, 2001.

ENSSLIN, L.; VIANNA, W. B. O design na pesquisa quali-quantitativa em engenharia de produção - questões epistemológicas. Revista Produção online, v. 8, n. 1, 2008.

FITZGERALD, L., Product costing in service organisations. Management Accounting Research, v. 2, n. 4, p. 227-248, 1991.

GARENGO, P.; BIAZZO, S.; BITITCI, U. S. Performance measurement systems in SMEs: A review for a research agenda. International Journal of Management Reviews, v. 7, n. 1, p. 25-47, 2005.

GEROLAMO, M. C.; ESPOSTO, K. F.; CARPINETTI, L. C. R. Modelo para identificação de ações de melhoria de desempenho alinhadas à estratégia. Revista Produção online, 2003.

GIL, A. C. Como elaborar projetos de pesquisa. 3. ed. São Paulo: Atlas, 1999.

GOLDSZMIDT, R. G. B.; PROFETA, R. A. Implementação da estratégia: um estudo de caso da interação BSC - PNQ. Revista Alcance, v. 11, n. 1, p. 101-119, 2004.

HAN, D.; HAN, I. Prioritization and selection of intellectual capital measurement 
indicators using analytic hierarchy process for the mobile telecommunications industry. Expert Systems with Applications, v. 26, n. 4, p. 519-527, 2004.

HENDRIKSEN, E. S.; VAN BREDA, M. F. Teoria da contabilidade. 5. ed. São Paulo: Atlas, 1999.

JACOBSEN, K.; HOFMAN-BANG, P.; NORDBY JR, R. The IC Rating? model by intellectual capital sweden. Journal of Intellectual Capital, v. 6, n. 4, p. 570-587, 2005.

KAPLAN, R. S.; NORTON, D. P. Having trouble with your strategy? Then map it. Harvard Business Review, v. 78, n. 5, p. 167-176, 202, 2000.

KAPLAN, R.; NORTON, D. The Balanced Scorecard: the measures that drive performance. Harvard Business Review, jan./fev., p. 71-79, 1992.

KAPLAN, R.; NORTON, D. Using the Balanced Scorecard as a strategic management system. Harvard Business Review, jan-fev, p. 75-85, 1996.

KAPLAN, R. S; NORTON, D. P. A estratégia em ação: Balanced Scorecard. Rio de Janeiro: Campus, 1997.

KARDEC, A.; FLORES, J.; SEIXAS, E. Gestão estratégica e indicadores de desempenho. Manutenção Coleção. RJ: Qualitymark, 2002. p. 41- 43

KEEGAN, D. P; EILER, R. G.; JONES, C. R. Are your performance measures obsolete? Management Accounting, n. 70, p. 45-50, 1989.

KEENEY, R. L. Value focused-thinking: a path to creative decision-making. Cambridge: Harvard Univ. Press, 1992.

KENNERLY, M.; NEELY, A. Performance measurement framework - a review. In: Performance measurement - past, present and future. UK: Andy Neely, Centre for Business Performance, Cranfield School of Management, Cranfield University, Cranfield, Bedfordshire, 2000.

KIMURA, H.; SUEN, A. S. Ferramentas de análise gerencial baseadas em modelos de decisão multicriteriais. RAE-eletrônica, v. 2, n. 1, 2003.

LACERDA, R. T. O.; ENSSLIN, L.; ENSSLIN, S. R. Gerenciamento de portfólio e avaliação de desempenho. MundoPM, v. 29, p. 60-69, 2009.

LACERDA, R. T. O.; ENSSLIN, L.; ENSSLIN, S. R. A performance measurement view of IT project management. The International Journal of Productivity and Performance Management, v. 60, p. 132-151, 2011a.

LACERDA, R. T. O.; ENSSLIN, L.; ENSSLIN, S. R. A Performance measurement framework in portfolio management: a constructivist case. Management Decision, $v$. 49 , p. $1-15,2011 b$. 
LAITINEN, E. Framework for small business performance measurement: towards integrated PM system. Research Papers of the University of Vaasa, Finland, 1996.

LAITINEN, E. K. A dynamic performance measurement system: evidence from small Finnish technology companies. Scandinavian Journal of Management, v. 18, n. 1, p. 65-99, 2002.

LEV, V. Measuring the value of Intellectual Capital. Ivey Business Journal, v. 65, n. 4, p. 16-20, 2001.

LÖBLER, M. L.; HOPPEN, N. Validação de decisor, um sistema de apoio à decisão multicriterial para mapear processos decisórios. READ, v. 12, n. 1, 2006.

LYNCH, R; CROSS, K. Measure Up! yardsticks for continuous improvement. Cambridge: Blackweel, 1991.

MACEDO, M. A. D. S.; SILVA, F. D. F. D.; SANTOS, R. M. Análise do mercado de seguros no brasil: uma visão do desempenho organizacional das seguradoras no ano de 2003. Revista Contabilidade e Finanças USP, v. Ed. Especial, p. 88-100, 2006.

MARTIN, N. C. Da contabilidade à controladoria: a evolução necessária. Revista Contabilidade e Finanças USP, v. 28, p. 7-28, 2002.

MIRANDA, V. U. P. D. C. Construtivismo e racionalismo como paradigmas para modelos de tomada de decisão estratégica. REA-Revista Eletrônica de Administração, 2006.

MORAES, L.; GARCIA, R.; ENSSLIN, L.; CONCEIÇÃO, M. J. . The Multicriteria analysis for construction of benchmarkers to support the clinical engineering in the healthcare technology management. European Journal of Operational Research, v. 200 , p. $607-615,2010$.

NEELY, A.; GREGORY, M. Performance measurement system design. International Journal of Operations \& Producy Management, v. 15, 1995.

NEELY, A; ADMS, C.; KENNERLEY, M. The performance prism: the socrecard for measuring and managing stakeholder relationship. London: Prentice Hall, 2002.

NEELY, A; GREGORY, M.; PLATTS, K. Performance measurement system design. A literature review and research agenda. International Journal of Operations \& Production Management, v. 25, n. 12, p. 1228-1263, 2005.

PACE, E. S. U.; BASSO, L. F. C.; SILVA, M. A. D. Indicadores de desempenho como direcionadores de valor. RAC, v. 7, n. 1, p. 37-65, 2003. 
PUNNIYAMOORTHY, M.; MURALI, R. Balanced score for the balanced scorecard: a benchmarking tool. Benchmarking: An International Journal, v. 15, n. 4, p. 420443, 2008.

RICHARDSON, R. J. Pesquisa social: métodos e técnicas. 3. ed. São Paulo: Atlas, 2008.

ROBERTS, F. S. Measurement Theory. In: ROTA, G. C. (Ed.) Encyclopedia of mathematics and its applications, v. 7, London: Addison-Wesley Publishing Company, 1979.

SAATY, T. Multicriteria decision making. University of Pittsburg, 1988.

SANTOS, A. D.; CASA NOVA, S. P. D. C. Proposta de um modelo estruturado de análise de demonstrações contábeis. RAE-Eletrônica, v. 4, n. 1, 2005.

SCHNEIDER, C.; NETO, L. M. Avaliação do desempenho organizacional da empresa familiar indústrias Alfa S.A. com base no modelo de gestão estratégica balanced scorecard. REGE - USP, v. 13, n. 1, p. 89-104, 2006.

SOMENSI, U. F.; TONTINI, G. O balanced scorecard e seu inter-relacionamento com outros métodos de gestão. Revista de Negócios, v. 6, n. 1, p. 23-31, 2001.

STEWART, T. A. Capital intelectual: a nova vantagem competitiva das empresas.

Rio de Janeiro: Campus, 1998.

SVEIBY, K. E. A nova riqueza das organizações. Rio de Janeiro: Campus, 1998.

TUOMELA, T. S. The interplay of different levers of control: A case study of introducing a new performance measurement system. Management Accounting Research, v. 16, n. 3, p. 293-320, 2005.

VEGINI, D.; BACK, F .T.; ENSSLIN, L.; SOUZA, M. ENSSLIN, S. R.; MACHADO, T. Modelo de avaliação de desempenho de fogões com foco em ergonomia, utilizando o método MCDA-C. Revista Produção online, v. 12, n. 2, p. 423-454, 2012.

WERNKE, R.; BORNIA, A. C. A Contabilidade gerencial e os métodos multicriteriais. Revista Contabilidade e Finanças USP, v. 14, n. 25, p. 60-71, 2001.

YEO, Roland. The tangibles and intangibles of organisational performance. Team Performance Management, v. 9, n. 7/8, p. 199-204, 2003.

YIN, R. K. Estudo de Caso: planejamento e métodos. 3. ed. Porto Alegre: Bookman, 2005.

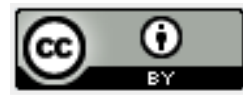

Artigo recebido em 17/09/2010 e aceito para publicação em 01/03/2013. 